\title{
A Time and a Place for Everything: Phylogenetic history and geography as joint predictors of oak plastome phylogeny
}

\begin{tabular}{|r|l|}
\hline Journal: & Genome \\
\hline Manuscript ID & gen-2016-0191.R1 \\
\hline Manuscript Type: & Article \\
\hline Date Submitted by the Author: & 15 -Mar-2017 \\
\hline Complete List of Authors: & $\begin{array}{l}\text { Pham, Kasey; Michigan State University, Department of Plant Biology; The } \\
\text { Morton Arboretum } \\
\text { HIPP, ANDREW; The Morton Arboretum, ; The Field Museum, Botany } \\
\text { Manos, Paul; Duke University, Department of Biological Sciences } \\
\text { Cronn, Richard; USDA Forest Service Pacific Northwest Research Station }\end{array}$ \\
\hline $\begin{array}{r}\text { Please Select from this Special } \\
\text { Issues list if applicable: }\end{array}$ & Evolution of Tree Diversity \\
\hline Keyword: & $\begin{array}{l}\text { Gene flow, Hybridization, Partial Mantel test, Plastome sequencing, } \\
\text { Restriction-site associated DNA (RADseq) }\end{array}$ \\
\hline \multicolumn{2}{|c}{} \\
\hline
\end{tabular}

\section{SCHOLARONE}

Manuscripts 


\section{A Time and a Place for Everything:}

Phylogenetic history and geography as joint predictors of oak plastome phylogeny

$$
\text { K.K. Pham }{ }^{1,2} \text {, A.L. Hipp }{ }^{1,3} \text {, P.S. Manos }{ }^{4} \text {, and R.C. Cronn }{ }^{5}
$$

${ }^{1}$ The Morton Arboretum, 4100 Illinois Route 53, Lisle IL 60532-1293, U.S.A.

${ }^{2}$ Michigan State University, Department of Plant Biology, East Lansing MI 48824-1312, U.S.A.

${ }^{3}$ The Field Museum, 1400 S Lake Shore Dr, Chicago, IL 60605, U.S.A.

${ }^{4}$ Duke University, Department of Biology, Durham, NC 27708-0338, U.S.A.

${ }^{5}$ Pacific Northwest Research Station, 3200 SW Jefferson Way Corvallis, OR 97331-4401, U.S.A.

Corresponding authors: K.K. Pham and A.L. Hipp (email: kase.khanh.pham@gmail.com, ahipp@,mortonarb.org) 


\section{Abstract}

Due to high rates of introgressive hybridization, the plastid genome is poorly suited to fine-scale DNA barcoding and phylogenetic studies of the oak genus (Quercus, Fagaceae). At the tips of the oak plastome phylogeny, recent gene migration and reticulation generally cause topology to reflect geographic structure, while deeper branches reflect lineage divergence. In this study, we quantify the simple and partial effects of geographic proximity and nucleome-inferred phylogenetic history on oak plastome phylogeny at different evolutionary scales. Our study compares pairwise phylogenetic distances based on complete plastome sequences, pairwise phylogenetic distances from nuclear restriction site-associated DNA sequences (RADseq), and pairwise geographic distances for 34 individuals of the white oak clade representing 24 North American and Eurasian species. Within the North American white oak clade alone, phylogenetic history has essentially no effect on plastome variation, while geography explains $11-21 \%$ of plastome phylogenetic variance. However, across multiple continents and clades, phylogeny predicts $30-41 \%$ of plastome variation, geography $3-41 \%$. Tipwise attenuation of phylogenetic informativeness in the plastome means that in practical terms, plastome data has little use in solving phylogenetic questions, but can still be a useful barcoding / phylogenetic marker for resolving questions among major clades.

Keywords: gene flow, hybridization, partial Mantel test, plastome sequencing, restriction-site associated DNA (RADseq) 


\section{Introduction}

Oaks have long been notorious among biologists for both high intraspecific morphological variation and low reproductive barriers (e.g. Wiegand 1935; Muller 1952; Burger 1975; Hardin 1975). Van Valen (1976) famously wrote, "It may well be that Quercus macrocarpa in Quebec exchanges many more genes with local $Q$. bicolor than it does with $Q$. macrocarpa in Texas" (Van Valen 1976: 235). Other studies have since confirmed that while oak species with overlapping ranges exchange alleles through introgressive hybridization (Whittemore \& Schaal 1991; Cavender-Bares \& Pahlich 2009; Peñaloza-Ramírez et al. 2010), these events are rare relative to the rate of intraspecific gene flow (Muir et al. 2000; Hipp and Weber 2008; Cavender-Bares et al. 2009; Gerber et al. 2014). This asymmetry of rates helps to maintain species boundaries even in sympatry and the genetic coherence of oak species over large geographic ranges. It appears that high rates of intraspecific gene exchange ensure that introgressant alleles remain at low frequencies (Petit and Excoffier 2009), increasing their chance of loss through drift. Thus gene flow among conspecific populations counterbalances the homogenizing effect of hybridization in the oak nuclear genome, making nuclear DNA a reliable source of phylogenetic data (Eaton et al. 2015; Hipp 2015).

The plastid genome, long the workhorse of angiosperm phylogenetics (Chase et al. 1993; Ruhfel et al. 2014; Shaw et al. 2014 and references therein), is haploid and non-recombinant, and it has a smaller effective population size than nuclear alleles. These factors increase the rate of fixation of haplotypes within populations and species via drift. Moreover, maternally inherited plastids typically have lower rates of among-population migration, reducing their effectiveness in maintaining species cohesion (Petit and Excoffier 2009). For these reasons, the plastome often tracks patterns of geographically structured interspecific gene flow that dominates in lineages at 
recent phylogenetic scales (e.g. Rieseberg and Soltis 1991; Rieseberg et al. 1991; Whittemore and Schaal 1991; Sang et al. 1997; Petit and Excoffier 2009) and can reveal evidence of hybridization history at even deep phylogenetic scales (Folk et al. 2016). These and related studies demonstrate that while phylogeny frequently tracks geography at broad scales, localized interspecific gene flow is often detectable at finer scales through conflict between plastomic and genomic phylogenies. Forest trees in particular frequently demonstrate plastome divergence patterns that conflict with known lineage divergence history (phylogeny), reflecting either the sorting of plastome lineages in large populations across large geographic regions or contemporary hybridization among interfertile species (Hamzeh and Dayanandan 2004; Shaw et al. 2012). Numerous studies of oaks have demonstrated that plastome haplotypes are shared freely among species of the same section, and that these haplotypes tend to cluster by geography instead of population divergence history or phylogenetic relationships (Whittemore and Schaal 1991; Petit et al 1993; Dumolin-Lapegue 1997; Simeone et al. 2016). At deeper phylogenetic scales, however, the plastome appears to track the monophyly of species within the major oak clades, whereas nuclear data provide evidence for higher order relationships among those clades (Manos et al. 1999; Oh and Manos 2008). The plastome may be thought of as complementary to the nuclear genome in oaks (Manos et al. 1999), providing resolution for ambiguous nuclear relationships near the base of the clade while reconstructing patterns of contemporary interspecific gene flow and introgression. The latter may be more weakly captured in the nuclear genome, where recombining loci differentially track segregation of ancestral alleles, population divergence, and ongoing gene flow (Via and West 2008).

Phylogeny and gene flow are typically considered separate targets of inquiry: studies investigating phylogeny generally treat gene flow as a nuisance factor, while studies of gene 
flow frequently ignore the contribution of phylogenetic history to variation observed in their molecular genetic datasets. Our study presents a novel approach to estimating the relative contributions of both phylogenetic signal and geographic proximity (a covariate of local gene flow) to patterns of oak plastome variation at different phylogenetic levels. We use whole plastome assemblies, nuclear restriction site-associated DNA sequencing (RADseq) data, and geographic source information to examine the joint and partial effects of population divergence history and local gene flow on the plastome phylogeny in white oaks (Quercus L. section Quercus) and intermediate oaks (Quercus section Protobalanus (Trelease) A.Camus).

\section{Materials and methods}

\section{Sampling}

43 RADseq and 45 plastome samples were drawn from the distribution of white and intermediate oaks (sections Quercus and Protobalanus respectively) across North America to detect phylogeographic structure at a continental scale; 33 of these samples overlapped between datasets. Three Eurasian white oak species (Quercus mongolica Fisch. ex Ledeb.; Q. petraea (Mattuschka) Libel.; Q. robur L.) were included for both datasets to assess geographic and phylogenetic structure between North America and Eurasia based on RADseq and plastome data. An additional 51 white oak samples focused predominantly on four Eurasian white oak species (the three aforementioned, plus $Q$. dentata Thunb.) were also surveyed for plastome variation to more exhaustively assess plastome phylogenetic and geographically-structured genetic variation among North American, European, and Asian white oaks. The total number of plastome sequences reported here is 91. A previously published red oak plastid genome (Quercus rubra 
L.; NCBI NC_020152) was included as an outgroup, and one RADseq sample from a different individual was added as the RADseq outgroup. Thus the total number of RADseq samples presented in this paper is 47. Geographic coordinates (latitude and longitude) were collected for source trees using a GPS.

\section{Restriction-site associated DNA sequencing}

RADseq DNA extraction, library preparation, and sequencing were conducted as presented previously by ALH and colleagues (Hipp et al. 2014; Eaton et al. 2015; CavenderBares et al. 2015). Briefly, DNA for all RADseq samples was extracted from fresh or frozen material using the DNeasy plant extraction protocol (DNeasy, Qiagen, Valencia, CA). DNA extractions were gel-quantified in agarose by visual comparison with the New England BioLabs 100 bp DNA Ladder (NEB, Ipswich, MA). Extraction concentrations ranged from 5-10 ng DNA / $\mu$ l extraction. RAD sequencing library preparation was conducted at Floragenex, Inc. (Portland, OR, USA) following the methods of Baird et al. (2008) with PstI. RAD libraries were barcoded by individual and multiplexed on an Illumina Genome Analyzer IIx. Sequencing reads were 100 bp in length; after removal of the barcode and recognition sequence, analyzed sequences were 85 bp long. Quality, read lengths, and base composition of FASTQ data were assessed in R v. 3.3.1 (“Bug in your hair"; R Core Team 2016) using the ShortRead package (Morgan et al. 2009).

\section{RADseq clustering}

Data were analyzed using the PyRAD pipeline (Eaton 2014; www.dereneaton.com/software). In this pipeline, sequences were clustered first by individual, and highly similar sequences are clustered into "stacks." In pyRAD, these stacks were generated using VSEARCH (Rognes et al. 2016), which allows sequences within clusters to vary in indels, nucleotide polymorphisms, and sequencing strand (direction). After clustering, heterozygosity 
and sequencing error were jointly estimated from the base counts observed across all sequences, sites, and clusters using the likelihood equation of Lynch (2008). Heterozygotes were inferred by a binomial probability based on these parameters. Bases that could not be assigned with $\geq 95 \%$ probability were treated as unknown $(N)$. Any locus possessing more than 2 haplotypes within individuals after correcting for sequencing errors was discarded, under the assumption that it included one or more paralogous sequences. For each individual, each locus was summarized as a consensus sequence, and consensus sequences were clustered among individuals to generate a data matrix for each locus. Due to variation in sequencing coverage and mutation at the restriction site defining $\mathrm{RAD}$ loci, the resulting data matrix was not complete for all loci in all individuals. The following parameters were specified for pyRAD: Minimum depth of reads per within-sample cluster: 6; maximum number of sites in a read which can have a quality score of less than twenty: 4; clustering threshold (percent similarity): 0.85; minimum number of samples in each across-sample cluster: 4; maximum number of individuals with a shared heterozygous site in an across-sample cluster: 3 . All other settings used default values.

\section{RADseq data matrix}

After clustering, consensus sequences of resulting RADseq loci were produced in R ( $R$ Core Team 2016) using the RADami package (Hipp 2014) and mapped to a complete Quercus rubra oak plastome using Bowtie2 (Langmead and Salzberg 2012) with default settings. Loci with a positive match to the plastome were removed using RADami. Samples of the western North American Q. gambelii Nutt. were initially included, but preliminary analyses of the dataset demonstrated that $Q$. gambelii samples in combination with $Q$. macrocarpa Michx. destabilize the white oak RADseq phylogeny, suggesting a complex genomic composition that could be the product of hybridization and that is beyond the scope of the current paper. This issue is 
addressed in a separate paper in this volume (McVay et al., current issue), but in brief, inclusion of $Q$. gambelii has the effect of pulling $Q$. lobata Née toward Q. macrocarpa and relatives, at odds with all nuclear data. Samples of $Q$. gambelii were therefore removed from the RADseq dataset for final analyses. RADseq loci were subsetted for alternative analyses presented below and concatenated for analysis in RAxML (Stamatakis 2014) using RADami and exported as a FASTA file. Concatenation order was the numerical sort order of the locus names, which are assigned arbitrarily during the clustering pipeline implemented in pyRAD.

\section{Plastome sequencing and plastome assembly}

Individual DNA aliquots $(0.5-1 \mathrm{~g})$ were sheared to a median length of ca. $300 \mathrm{bp}$ and converted into individually indexed sequencing libraries using Illumina TruSeq v.2 kits at the USDA Forest Service (Corvallis, OR, USA), as described in Schroeder et al. (2016). Briefly, sequencing was performed using: the Illumina MiSeq with $2 \times 150$ bp paired-end reads to produce individual de novo genome reference assemblies for representative North American, European and Asian species (Quercus alba, Q. petraea and Q. mongolica respectively); and the Illumina HiSeq with $100 \mathrm{bp}$ single-end reads to sequence individual samples for reference-guided read mapping and genome assembly. All reactions used version 3 sequencing chemistry. Information on raw clusters, sequence yield, and approximate target sequence (plastid genome) coverage depth is provided in the supplements section (Supplement S2).

\section{Plastome data matrix}

Raw read quality filtering, de novo assembly, and reference guided assembly for these samples are described in Schroeder et al. (2016). Briefly, raw read quality filtering was 
accomplished using Trimmomatic v0.30 (Bolger et al. 2014) to remove reads with a mean Phred score less than 33. Reference guided read mapping and plastome assembly were performed using CLC Genomics Workbench v. 7.5.1 (CLC-Bio; Aarhus, Denmark) and the 135,258 bp Quercus mongolica draft plastid genome reference (accession MOR360 / QUMO5_CH_1; Schroeder et al. 2016). This chloroplast genome reference contains only one of the two inverted repeat regions that are present red oak chloroplast genomes (Alexander and Woeste 2014), so our reference size $(135.2 \mathrm{~kb})$ is smaller than a complete oak chloroplast genome $(\sim 161 \mathrm{~kb})$. Reads were mapped to the reference using a length fraction of 0.9 , a similarity fraction of 0.94 , a mismatch cost of 2 , and insertion/deletion costs of 6 . A minimum depth of 5 or greater was applied to call reference and non-reference bases; sites with a depth less than 5 were coded as N. Ingroup plastome assemblies were aligned in MAFFT v7.149b (Katoh and Standley 2013), using gap opening and extension penalties of 2.0 and 0.1 , respectively. The ingroup matrix was aligned to the Quercus rubra outgroup using MAFFT profile-profile alignment. The resulting alignment was edited manually in Geneious version R8 (http://www.geneious.com, Kearse et al. 2012), primarily to remove large insertions present in the ingroup plastome alignment. The resulting alignment was processed in gblocks (Castresana 2000), using default parameters for DNA to remove positions where differences in the ingroup and outgroup sequences resulted in erroneous or ambiguous alignments. Ambiguous positions (Ns) were retained in alignments and analysis except where gblocks removed them. Unlike in the RADseq matrix, Q. gambelii was retained in the plastome matrix, as intragenomic recombination / genealogical discordance is not an issue in the plastome.

\section{Phylogenetic analyses}

Phylogenetic analyses were conducted under maximum likelihood using RAxML v. 8.2.4 on the RADseq and plastome alignments separately. Given the size and complexity of the 
genomic data, we utilized the relatively parameter rich GTR+gamma model, under the GTRCAT approximation. For each dataset, bootstrap proportions were generated from 100 non-parametric bootstrap replicates and mapped to the internal branches of the ML tree. For computational reasons, we utilized fast bootstrapping (-f a option in RaxML) for all analyses presented in this paper. A comparison of fast bootstrapping with thorough bootstrapping (-b in RAxML) on the full plastome tree (Fig. 1) shows no systematic difference between bootstrapping methods (Supplment S1). Trees were rooted using Quercus rubra for both datasets.

\section{Modeling the effect of geography and population divergence history on plastome phylogeny}

The relative predictive power of phylogeny and geography on plastome similarity was estimated in R using the packages ape (Paradis et al. 2004) and phytools (Revell 2012) and the morton R library (https://github.com/andrew-hipp/morton). Cophenetic pairwise distances (branch length distances, estimated in RAxML according to the GTR+gamma nucleotide substitution model as described under Phylogenetic Analyses above) between all tips on a single tree were calculated for both the RADseq and plastome trees as our estimates of plastome pairwise dissimilarity $\left(\Delta_{\text {plast }}\right)$ and nuclear DNA pairwise dissimilarity $\left(\Delta_{\text {nuc }}\right)$. Latitude and longitude data for the samples were used to calculate the geographic distance between samples $\left(\Delta_{\text {geog }}\right)$ using the Haversine formula as implemented in the morton library. Multiple and partial correlation coefficients were estimated, with Mantel permutations to assess significance (Mantel 1967; Smouse et al. 1986; Diniz-Filho 2013), on the following regression models: plastome variation predicted by both gene flow and nuclear genetic variation $\left(\Delta_{\text {plast }} \sim \Delta_{\text {geog }}+\Delta_{\text {nuc }}\right)$; plastome variation predicted by gene flow alone $\left(\Delta_{\text {plast }} \sim \Delta_{\text {geog }}\right)$; plastome variation predicted by nuclear genetic variation alone $\left(\Delta_{\text {plast }} \sim \Delta_{\text {nuc }}\right)$; and nuclear genetic variation predicted by gene flow alone $\left(\Delta_{\text {nuc }} \sim \Delta_{\text {geog }}\right)$. Only the position of samples in the response matrix was permuted, 
under the assumption that the prediction matrices were known without error (Smouse et al. 1986).

To assess how a dataset's phylogenetic depth affects the partial effects of lineage divergence history and gene flow on plastome variation, the dataset was pruned to several different phylogenetic levels and the Mantel tests described above were performed on each. The pruned datasets are: (1) all oaks sampled ( $\mathrm{N}=33$ samples), in which trees are pruned to only tips shared between the RADseq and plastome trees. This dataset contains both Eurasian and North American oaks in sections Quercus (the white oaks) and Protobalanus (the intermediate oaks). It spans the widest geographic range and largest phylogenetic scale. (2) The North American oaks $(\mathrm{N}=30$ samples): excludes the Eurasian white oaks from all oaks sampled. This exclusion set allows us to test whether geographic signal in the plastome is amplified by studying populations separated an ocean. (3) The North American white oaks ( $\mathrm{N}=25$ samples): excludes the intermediate oaks (section Protobalanus) from the North American oak dataset. This exclusion set allows us to examine the effects of removing a large source of phylogenetic signal in the plastome. While there is one North American white oak (Q. engelmannii Greene) that has been shown to harbor a Protobalanus plastome (Manos et al. 1999), there is no evidence of ongoing gene flow between these two, and we know of no other cases of interbreeding between white oaks and intermediate oaks. (4) The North American oaks without California white oaks $(\mathrm{N}=21$ samples): excludes California oaks from the North American oak dataset. The California white oaks excluding Q. engelmannii are a well defined clade (Sork et al. 2016) unlikely to exchange alleles with eastern North American oaks, making the California oaks another potential source of phylogenetic signal in the plastome. This exclusion set is analogous to the North American white oak dataset, q.v. The inclusion of the intermediate oaks but 
exclusion of California oaks tests whether gene flow and phylogenetic signal is comparable with either of the two western North American clades present in our dataset. (5) The eastern North American white oaks ( $\mathrm{N}=19$ samples): excludes the Californian oaks and a clade of derived Mexican and southwestern North American oaks (represented in our study by Q. arizonica Sarg., Q. engelmannii, Q. vaseyana Buckley, and Q. mohriana Buckley ex Rydb.) from the North American white oak dataset. This exclusion set is paraphyletic but concentrates the partial Mantel tests on just the potentially interbreeding eastern North American oaks, one that has been particularly challenging to oak systematists (e.g. Hardin 1975). All exclusion sets are summarized in Supplement S3.

\section{Results}

\section{RADseq clustering and data matrix}

RADseq sequencing runs produced $8.43 \times 10^{5}$ to $3.49 \times 10^{6}$ sequences per individual, with a mean of $2.16 \times 10^{6} \pm 1.87 \times 10^{6}$ (s.d.). Sequencing quality averages nearly 40 (out of 40 ) across bases 1-60, with high quality averaged across all runs (mean quality score $=36.7 \pm 0.536$ s.d.). Including the outgroup Quercus rubra, the RADseq library comprises 48 individuals and $6.92 \times 10^{4}$ loci, spanning 80 to $118 \mathrm{bp}$, with an average length of $87.6 \mathrm{bp} \pm 2.90$ s.d. The number of loci returned for single individuals ranges from $1.81 \times 10^{4}$ to $3.58 \times 10^{4}$, with a mean of 2.66 $\times 10^{4} \pm 4.07 \times 10^{3}$ s.d. The number of variable sites per locus averages $7.58 \pm 5.62$ s.d.

Seven loci (loci 508, 5924, 11871, 34638, 23273, 51846, 69261) mapped back to the Quercus rubra plastid reference genome and were omitted from locus concatenation. In the $Q$. rubra plastome utilized in this study, there are 13 Pst $\mathrm{I}$ cut sites, suggesting that closer to 26 
RADseq loci ought to have mapped back to the genome. However, several of these are in the inverted repeat region and may as a consequence have been collapsed into loci. Alternatively, our mapping may have underestimated the number of loci mapping back to the plastome. At any rate, even without removal of these seven loci, the plastome is a negligible contributor to the RADseq dataset, which we safely treat as a nuclear dataset in this study. Two Q. gambelii individuals (accession numbers MOR-387 and MOR-546) were also omitted from concatenation (see discussion above). Not including the outgroup, the final data matrix contains 45 individuals belonging to 25 species, and $6.06 \times 10^{6}$ nucleotide positions.

\section{Plastome data matrix}

Individual shotgun sequencing used for plastome assembly produced between $2.46 \times 10^{6}$ to $18.33 \times 10^{6}$ reads per individual, yielding $109 \times 10^{6}$ to $1,765 \times 10^{6}$ bases (mean values: 8.17 $\times 10^{6}$ reads and $763.5 \times 10^{6}$ bp per individual). Sequencing quality averaged $34.9 \pm 0.1 .73$ (s.d.) for 101 bp reads. Reference-guided mapping to the Quercus mongolica draft plastid genome reference (MOR360) showed that an average of $3.47 \%$ of sequence reads could be mapped to the reference (range: $0.36 \%$ to $9.33 \%$ ); this produced assemblies that averaged $204 \mathrm{X}$ depth and were nearly complete, with all sequences showing fewer than 350 N's (mean $=84)$. Assembly information can be found in the supplements section (S2). Alignment to the Quercus rubra reference plastid genome yielded a data matrix with 92 individuals, 26 species, and an overall length of $136,790 \mathrm{bp}$. Further refinement with gblocks removed $12,854 \mathrm{bp}$, resulting in a final matrix 132,936 bp in length. Alignments between white oaks (Quercus sect. Quercus) revealed 1852 ingroup variable sites across all genomes (including ambiguities), while adding members of Quercus sect. Protobalanus yielded an additional 306 ingroup variable sites (2158 total including ambiguities). The profile-to-profile plastome alignment is $136,790 \mathrm{bp}$ long once 
aligned with the Quercus rubra outgroup sequence, and contains 91 individuals comprising 26 species not including the outgroup. gblocks removes $3,854 \mathrm{bp}$ from the alignment, resulting in a final matrix that is $132,936 \mathrm{bp}$ long.

\section{Phylogenetic analyses}

The plastome ML tree (Fig. 1) exhibits four deep plastome lineages, each supported with $100 \%$ bootstrap support, and each confined to either North America (3 lineages) or Eurasia (one lineage). Sections Quercus and Protobalanus are both non-monophyletic in this tree, and one member of section Quercus (Q. engelmannii Greene) falls within an otherwise Protobalanusdominated plastome lineage, as reported previously (Manos et al. 1999). Section Protobalanus exhibits a deep polyphyly that was also reported in Manos et al. (1999), with two lineages that show no evidence of recent plastome sharing (Fig. 1): species in this section segregate for comparatively ancient plastomes that conflict with sectional circumscription. Numerous species within the white oaks are non-monophyletic in the plastome tree, with accessions clustering coarsely by geography. For example, Q. muehlenbergii Engelm. is represented by three individuals in the plastome analysis (Fig. 1), and two of these samples (MOR-632 and MOR383) do not resolve as closely related to the third sample (MOR-639). While this species together with $Q$. prinoides Willd. form a clade in the RADseq tree (Fig. 2), samples MOR-632 and MOR383 were collected from the eastern United States (IL, OK) and cluster with other samples from the same geographic region (e.g., Q. lyrata from Georgia, Q. macrocarpa from Kansas, Q. alba from Pennsylvania). In contrast, the outlier sample (MOR-639_ was collected from the Guadalupe Mountains of Texas, and it resolves with other samples (Q. mohriana Buckley ex Rydb. and Q. vaseyana Buckley) that were collected from the same geographic region in southwest Texas. 
The RADseq ML tree (Fig. 3, left) produced by the RADseq matrix shows a clear split between sections Quercus and Protobalanus (100\% bootstrap support for both clades). Within the white oaks (section Quercus), the California oaks are sister to the rest of the clade (bootstrap $=100 \%)$. The Eurasian oaks form a clade sister to all white oaks except for the California clade (bootstrap $=100 \%$ ). All taxa but Quercus macrocarpa Michx., Q. stellata Wangenh., $Q$. muehlenbergii, and Q. chrysolepis Liebm. are monophyletic, with 100\% bootstrap support for the bipartition grouping accessions representing each species. With the exception of the placement of the Eurasian white oaks, which fall sister to a small clade of eastern North American white oaks in Hipp et al. (2014), the topology of the tree concurs with this previous skeletal phylogeny of the oaks based on RADseq data, and all clades are strongly supported.

\section{Effect of geography and population divergence history on plastome phylogeny}

At the broadest phylogenetic and geographic scale ("all oaks"), geography and phylogeny are both strong, significant partial predictors of plastome variation (geography partial correlation: $r^{2}=0.412, p<0.002 ;$ phylogeny partial correlation: $r^{2}=0.382, p<0.002$; phylogeny simple correlation: $\mathrm{r}^{2}=0.311, \mathrm{p}<0.002$; Table 2). In the North American oaks, geography decreases in predictive power $\left(\mathrm{r}^{2}=0.028, \mathrm{p}=0.062\right.$; Table 2$)$, but phylogeny remains a strongly significant predictor of plastome variation $\left(\mathrm{r}^{2}=0.406, \mathrm{p}<0.002\right.$; Table 2$)$. The North American white oak dataset and the North American oak dataset without California each excludes one western North American clade (section Protobalanus and the California white oaks respectively) that exhibits little hybridization with non-California taxa. The two exclusion sets, however, exhibit different patterns of plastome prediction. Exclusion of section Protobalanus alone results in a dramatic decrease in the predictive power of phylogeny $\left(r^{2}=0.001, p=0.621\right.$; Table 2$)$. However, exclusion of the California white oaks results in an increase in predictive power of phylogeny 
from the North American oaks $\left(\mathrm{r}^{2}=0.300\right)$, though both phylogenetic and geographic signal are significant ( $\mathrm{p}<0.002$ for both). This result appears, however, to be due solely to the presence of the Mexican clade species Carex engelmannii, for its exclusion reduces partial correlations of phylogeny and geography to non-significance (Supplement S4). At the finest phylogenetic scale (the eastern North American white oaks), geographic signal and phylogeny are both nonsignificant predictors of plastome variation (Table 2).

\section{Discussion}

Phylogenetic incongruence between nuclear and plastid genome genealogies have been documented for diverse taxa over decades, using a variety of gene marker systems (Maddison 1997; Wendel and Doyle 1998). One common outcome of these studies is that organelle genome variation often tracks geographic genetic structure, while the nuclear genome appears to track evolutionary relationships as predicted by morphology or ecology (Whittemore and Schaal 1991). Our study is unique in its attempt to partition the effects of phylogeny and geography on the plastome nucleotide variation at varying phylogenetic depths in a lineage that is known to experience contemporary hybridization. We show that increasing the depth of the phylogeny considered increases the partial effect of phylogeny on the plastome topology, and that at the continental scale in North America, geography outweighs phylogeny as a predictor of plastome topology. We find, moreover, that the strong phylogeographic structure found in previous studies of European oaks (e.g. Dumolin-Lapegue et al. 1997) is not demonstrated in the eastern North American oaks, the classic oak syngameon (Hardin 1975; Burger 1975; Van Valen 1976). The deepest unambiguous split in the nuclear phylogeny, the split between the white oaks (section Quercus) and the intermediate oaks (section Protobalanus), is the single most important factor 
explaining concordance between the plastome phylogeny and population divergence history as encoded in the RADseq data. Inclusion of that split with the California species, however, reduces the fit between the RADseq and the plastome data, presumably because historic hybridization between section Protobalanus and California white oaks (as evidenced by incongruence in the placement of $Q$. engelmannii) erodes phylogenetic signal. Thus, joint analysis of nuclear and plastome data captures the interaction among biogeography, ancestral lineage divergences, and contemporary gene flow in the oaks, but within major clades of the genus, combined analysis is a poor method of inferring phylogenetic history.

\section{Phylogenetic analyses}

The recovery of phylogenetic structure among major clades and geographic signal at fine scales in the plastome tree is consistent with past studies, which have also found non-monophyly of species but geographic structuring of populations at fine scales based on plastome sequences (Dumolin-Lapegue 1991; Petit et al. 1993; Manos et al. 1999). The RADseq tree also returned expected relationships at fine interspecific levels, confirming relationships and monophyly of most species inspected (Pearse and Hipp 2009; Hipp et al. 2014). The paraphyly of Q. stellata in the RADseq tree derives, we suspect, from a relatively high rate of hybridization in this species (cf. Nixon and Muller 1997) that we do not investigate further in the current paper.

\section{Effect of geography and population divergence history on plastome phylogeny}

Hybridization in oaks is primarily limited to crosses within sections, with the exception of the single inferred case of historical hybridization between western North American Protobalanus and Quercus first reported in Manos et al. (1999) involving the white oak $Q$. engelmannii and corroborated in our study. We therefore expect the plastome to track deeper 
(more ancient) phylogenetic relationships, as seen in our results by the predictive power of the RADseq tree on the plastome topology in the all oaks sampled dataset. At the scale of all oaks sampled, the plastome topology is significantly predicted by geography in both simple and partial regressions, with the partial correlation coefficient $\left(r^{2}=0.406\right)$ slightly larger than the simple correlation coefficient $\left(r^{2}=0.338\right)$. This increase of $7 \%$ in variance explained from the simple to partial regression may reflect the fact that at the broadest phylogenetic scale in this study, there is substantial geographic structure embedded within the phylogenetic structure, and that a portion of this variation is only captured when phylogeny is controlled for using partial regression.

Removing Eurasian white oaks from this analysis has minimal effect on the proportion of plastome variation explained by the RADseq phylogeny (from $r^{2}=0.382$ to $r^{2}=0.407$ ). The phylogenetic placement of Eurasian white oaks has varied among published studies, with the group resolving as monophyletic sister to a subset of eastern North American white oaks (RADseq nuclear markers; Hipp et al. 2014), weakly monophyletic within the white oaks (six nuclear genes; Hubert et al. 2014), or strongly monophyletic and sister to the remainder of the white oaks (AFLP markers; Pearse and Hipp 2009; also plastid genomes in this study). The plastid genome and the nuclear genome consistently recover the Eurasian white oaks as a strongly supported clade; it is their placement within Quercus subg. Quercus that is uncertain in our study, and the deep divergence between the Eurasian white oaks and their sister taxa in the plastid genome tree (e.g., Fig. 1) contrast the more recent divergences indicated by the nuclear data (Fig. 2, left panel). As a consequence of these long branches, removing the Eurasian white oaks has the effect of focusing comparisons on the deepest divergences in both trees, such as the 
divergence of Protobalanus and the white oaks, and between Californian and Eastern North American oaks.

The deepest plastome divergences distinguish the two Protobalanus lineages, the Eurasian white oak lineage, and the North American white oak lineage. Thus, excluding both Protobalanus and the Eurasian white oaks from analysis removes the effect of nuclear phylogeny on the plastome topology (partial effect of RADseq variance on plastome variance decreases from $r^{2}=0.382$ to $\left.r^{2}=0.001\right)$. Major clades are recoverable in the plastome tree because there are stronger reproductive barriers among sections than within sections and among geographic regions. Removing both the strongest geographic outliers (viz., the Eurasian white oaks) and the members of the section Protobalanus restricts comparisons to a single major clade on a single continent. The plastome divergence between the California and eastern North American white oaks, which presumably have a very limited history of gene flow, is not nearly as deep as the break with either Protobalanus or the Eurasian white oaks, perhaps reflecting a history of gene flow among clades that postdates initial divergence. Thus the North American oaks, even with California included, shows much weaker correlation between the plastome topology and the RADseq phylogeny than the datasets that include the deepest plastome divergences.

An interesting finding from our genome-scale survey is evidence for two comparatively ancient plastome lineages in section Protobalanus. This recapitulates a finding of Manos et al. (1999) with far greater genome-scale resolution, albeit with shallower taxon sampling. In the prior study, members of Protobalanus formed two monophyletic lineages that were incompletely resolved in a basal polytomy. Sampling of Protobalanus in Manos et al. (1999) was sufficient to demonstrate that two divergent plastome types were segregating in at least two of the sampled species (Quercus chrysolepis, Q. palmeri Engelm.). This unusual level of polymorphism may 
reflect a very ancient gene exchange event between Protobalanus and a white oak lineage, or lineage sorting of ancient haplotypes: in our study, the divergence between Protobalanus plastomes corresponds to the crown node of the entire ingroup, and in Manos et al. (1999: 337), the two plastome clades differed by 13 restriction sites. The origin and taxonomic distribution of these two ancient plastome clades bears further study. Our plastome tree is also congruent with Manos et al. (1999) in placing Q. engelmannii Greene, a California white oak, in the same plastome group as Q. tomentella Engelm. Given the crown depth of each Protobalanus plastome clade (much younger than the divergence time between the Protobalanus plastomes), this placement almost certainly reflects more recent gene flow between white oaks and intermediate oaks. Stronger within-species sampling in a geographic context within the intermediate and California white oaks will be needed to evaluate how prevalent gene flow is between these sections.

Our analysis of the eastern North American white oaks contrasts sharply with previous studies on the European oaks (e.g. Dumolin-Lapegue et al. 1997), which have found strong phylogeographic signal. In the eastern North American oaks, plastome variation correlates poorly with both geographic and phylogeny (Table 2), unlike at the largest phylogenetic scales, where both geographic and phylogenetic signal are strong predictors because of the geographic structure embedded in phylogenetic signal (congruence of the two signals). In this classic eastern North American oak syngameon, it is remarkable that we do not find consistent geographic clustering across deep splits in the plastome tree within North America (Fig. 3). While our sampling should be sufficient to detect, for example, the Mississippi River discontinuity exhibited by numerous animals and a few plant species (Soltis et al. 2006), no node on the plastome tree supports a clean east-west phylogeographic split. The capacity for long-distance 
gene flow in oaks and their large population sizes may blur any signal of such phylogeographic breaks in eastern North America, where Pleistocene refugia were likely less discrete than in Europe.

In this study, we quantified the proportion of evolutionary history explained by plastome variation and contemporary geographic distributions. It is important to note, however, that for oaks and other temperate zone trees, current geographic distributions can be accurately modeled as a response to climatic variables (Rehfeldt et al. 2006; Roberts and Hamann 2012). This suggests that the correlations we observe between phylogeny and geography most likely have their origins in both adaptation to climate and the biogeography of diversification. The distributions of oaks and other temperate zone tree species have been in a continuous state of flux during Pleistocene-era climate change (Hewitt 1996 ; Roberts and Hamann 2015), with some species moving continental-scale distances of latitude and longitude (e.g., Quercus alba; Gugger et al., 2013; Q. petraea and Q. robur, Taberlet et al., 1998), and others migrating shorter geographic distances across elevational gradients (e.g. Q. garryana; Crookston 2016; Q. lobata, Gugger et al. 2013). This climate-driven migratory history is likely to be a major source of the 'geographic signal' and 'phylogenetic noise' we observe in eastern North American white oaks. Geographic signals may be enhanced via changes in population sizes (e.g., contraction during glacial maxima; expansion during interglacial episodes) or the exchange of haplotypes via rare hybridization events between species as they migrate into and out of common refugia (e.g., Taberlet et al. 1998). Climate envelope modelling and paleoclimate reconstructions are now being integrated to understand the role of past climates on contemporary species diversity (Roberts and Hamann 2015), and such analyses may help to dissect the individual contributions 
of phylogeny, geography and climate to contemporary genetic variation in such complex groups as the white oaks.

Finally, our findings have relevance to ongoing efforts to identify DNA barcodes (Hollingsworth et al. 2016), informative genetic markers that are diagnostic for oak species and related hybrids. Due to the ecological and economic importance of Quercus globally, there have been a few attempts to develop simple diagnostic markers for oak species identification for use in ecological/landscape inventories (Simeone et al. 2012), conservation management, and screening oak wood products suspected as being derived from exploited sources (Schroeder et al. 2016). For example, Q. mongolica is listed as a CITES Appendix III species due to pressure from illegal logging in the far-east of the Russian Federation (U.S. Department of Justice 2015); this status restricts trade of $Q$. mongolica, and brings all commercial species of white oak under greater scrutiny for labeling accuracy. Due to their high similarity, Q. mongolica cannot be discriminated from other white oak species by wood anatomy, leaving DNA-based detection as one of the few available tools for identifying the taxonomic source of wood and enforcing illegal logging laws (Dormontt et al. 2015).

Our survey of 91 complete plastid genomes (Fig. 1) shows that organelle genomes are frequently shared across diverse evolutionary lineages and species. Indeed, of the 15 species represented by multiple sequences in our study, plastome monophyly was only observed in one case (Q. gambelii), and this seems likely to be a consequence of limited sampling. This result, combined with other barcoding efforts in Quercus (Piredda et al. 2010; Simeone et al. 2012), suggest that plastid genome sequences - either as subsets of barcode genes, or as the complete genomic 'ultrabarcode' (Coissac et al. 2016) - are highly unlikely to offer the precision required for confident identification of source species, unless they are accompanied by additional 
information from the nuclear genome. In this regard, oak joins a growing list of woody species that cannot be "barcoded" with a single genome (Arca et al. 2012; Clement and Donoghue 2012; Parks et al. 2012; Percy et al. 2014) and that will require additional information from multiple genomes and multiple loci for accurate species identification. Our study does, however, confirm that a substantial proportion of variation in the plastome can be explained by geography (e.g., Table 2; Figs. 1,2). This should make it possible to develop markers and databases that can address questions of geographic origin, as has recently been accomplished for the Asian white oaks Q. mongolica and Q. dentata (Schroeder et al. 2016).

\section{Acknowledgments}

This study was funded by National Science Foundation awards to ALH (Awards 1146488, 1255901) and PSM (Award 1146102), USDA Forest Service International Programs Office (RCC), the German Federal Ministry of Food and Agriculture and the Deutsche Bundesstiftung Umwelt (BD), and the US Agency for International Development and US Department of State (RCC, BD). We especially acknowledge Marlene Hahn (The Morton Arboretum, Lisle, IL, USA, Corvallis, OR, USA) for sample preparation and curation of metadata and specimens for the RADseq dataset; Tara Jennings (Pacific Northwest Research Station, Corvallis, OR, USA) for sample preparation and sequence assembly of the plastid genome dataset; and Mark Dasenko, Matthew Peterson, and Chris Sullivan (Oregon State University Center for Genome Research and Biocomputing, Corvallis, OR, USA) for assistance with sequencing. We thank Brad Kinder, Alex Moad, and Shelley Gardner (US Forest Service, Washington D.C.) for project coordination

to obtain Asian oak samples, Bernd Degen (Johann Heinrich von Thünen Institut, Grosshansdorf, Germany) and Yulai Yanbaev (Bashkir State University, Ufa, Russia) for coordinating Russian 
oak collections, and a long list of collaborators who provided specimens for this study (identified in supplement). Finally, we thank Aaron Liston (Oregon State University) and others for their input on this project and the resulting manuscript, and the editors and reviewers of Genome for their insightful comments on the first version of this paper.

\section{References}

Alexander L.W., and Woeste K.E. 2014. Pyrosequencing of the northern red oak (Quercus rubra L.) chloroplast genome reveals high quality polymorphisms for population management. Tree Genetics and Genomes 10(4): 803-812.

Arca M., Hinsinger D.D., Cruaud C., Tillier A., Bousquet J., and Frascaria-Lacoste N. 2012. Deciduous trees and the application of universal DNA barcodes: A case study on the circumpolar Fraxinus. PLoS ONE 7:e34089. doi:10.1371/journal.pone.0034089.

Baird, N.A., Etter, P.D., Atwood, T.S., Currey, M.C., Shiver, A.L., Lewis, Z.A., et al. 2008. Rapid SNP discovery and genetic mapping using sequenced RAD markers. PLoS ONE 3(10): e3376. doi:10.1371/journal.pone.0003376.

Bolger, A.M., Lohse, M., and Usadel, B. 2014. Trimmomatic: a flexible trimmer for Illumina sequence data. Bioinformatics 30: 2114-2120.

Burger, W.C. 1975. The species concept in Quercus. Taxon 24: 45-50.

Castresana, J. 2000. Selection of conserved blocks from multiple alignments for their use in phylogenetic analysis. Molecular Biology and Evolution 17: 540-552. 
Cavender-Bares, J., and Pahlich, A. 2009. Molecular, morphological, and ecological niche differentiation of sympatric sister oak species, Quercus virginiana and Q. geminata (Fagaceae). American Journal of Botany 96: 1690-1702.

Cavender-Bares, J., Gonzalez-Rodriguez, A., Eaton, D.A.R., Hipp, A., Buelke, A., and P. Manos. 2015. Phylogeny and biogeography of the American live oaks (Quercus subsection Virentes): A genomic and population genetic approach. Molecular Ecology 24: 3668-3687. doi:10.1111/mec.13269.

Chase, M.W., Soltis, D.E., Olmstead, R.G., Morgan, D., Les, D.H., Mishler, B.D., Duvall, M.R., Price, R.A., Hills, H.G., Qiu, Y.-L., Kron, K.A., Rettig, J.H., Conti, E., Palmer, J.D., Manhart, J.R., Sytsma, K.J., Michaels, H.J., Kress, W.J., Karol, K.G., Clark, W.D., Hedren, M., Gaut, B.S., Jansen, R.K., Kim, K.-J., Wimpee, C.F., Smith, J.F., Furnier, G.R., Strauss, S.H., Xiang, Q.-Y., Plunkett, G.M., Soltis, P.S., Swensen, S.M., Williams, S.E., Gadek, P.A., Quinn, C.J., Eguiarte, L.E., Golenberg, E., Learn, G.H., Graham, S.W., Barrett, S.C.H., Dayanandan, S., and Albert, V.A. 1993. Phylogenetics of seed plants: an analysis of nucleotide sequences from the plastid gene $r b c \mathrm{~L}$. Annals of the Missouri Botanical Garden 80(3): 528-580. doi:10.2307/2399846.

Clement, W.L., and Donoghue, M.J. 2012. Barcoding success as a function of phylogenetic relatedness in Viburnum, a clade of woody angiosperms. BMC Evolutionary Biology 12: 73 doi: $10.1186 / 1471-2148-12-73$.

Coissac E., Hollingsworth P.M, Lavergne S., and Taberlet, P. 2016. From barcodes to genomes: extending the concept of DNA barcoding. Molecular Ecology 25:1423-1428. 
Crookston, N.. 2016. Research on forest climate change: Potential effects of global warming on forests and plant climate relationships in Western North America and Mexico [online]. Available from http://charcoal.cnre.vt.edu/climate/. [accessed: 10/17/2016]

Diniz-Filho, J.A.F., Soares, T.N., Lima, J.S., Dobrovolski, R., Landeiro, V.L., de Campos Telles, M.P., Rangel, T.F., and Bini, L.M. 2013. Mantel test in population genetics. Genetics and Molecular Biology 36(4): 475-485. doi:10.1590/S1415-47572013000400002.

Dormontt, E.E., Boner, M., Braun, B., Breulmann, G., Degen, B., Espinoza, E., Gardner, S., Guillery, P., Hermanson, J.C., Koch, G., Lee, S.L., Kanashiro, M., Rimbawanto, A., Thomas, D., Wiedenhoeft, A.C., Yin, Y., Zahnen, J., and Lowe, A.J. 2015. Forensic timber identification: It's time to integrate disciplines to combat illegal logging. Biological Conservation 191:790-798.

Dumolin-Lapegue S., Demesure, B., Fineschi, S., Le Corre, V., and Petit, R.J. 1997. Phylogeographic structure of white oaks throughout the European continent. Genetics 146: $1475-1487$.

Eaton, D.A.R. 2014. PyRAD: assembly of de novo RADseq loci for phylogenetic analyses. Bioinformatics 30(13): 1844-1849. doi: 10.1093/bioinformatics/btu121.

Eaton, D.A.R., Hipp, A.L., González-Rodríguez, A. and Cavender-Bares, J. 2015. Historical introgression among the American live oaks and the comparative nature of tests for introgression. Evolution 69: 2587-2601. doi:10.1111/evo.12758

Folk, R.A., Mandel, J.R., and Freudenstein, J.V. 2016. Ancestral gene flow and parallel organellar genome capture result in extreme phylogenomic discord in a lineage of angiosperms. Systematic Biology: syw083. doi:10.1093/sysbio/syw083. 
Gerber, S., Chadœuf, J. , Gugerli, F., Lascoux, M., Buiteveld, J., Cottrell, J., Dounavi, A., Fineschi, S., Forrest, L.L., Fogelqvist, J., Goicoechea, P.G., Jensen, J.S., Salvini, D., Vendramin, G.G., and Kremer, A.. 2014. High rates of gene flow by pollen and seed in oak populations across Europe. PLoS ONE 9: e85130.

Gugger, P.F., Ikegami, M., and Sork, V.L. 2013. Influence of late Quaternary climate change on present patterns of genetic variation in valley oak, Quercus lobata Nee. Molecular Ecology 22:3598-3612. doi: 10.1111/mec.12317.

Hamzeh, M., and Dayanandan, S. 2004. Phylogeny of Populus (Salicaceae) based on nucleotide sequences of chloroplast $\operatorname{trn} \mathrm{T}-\operatorname{trn} \mathrm{F}$ region and nuclear rDNA. American Journal of Botany 91(9): 1398-1408. doi:10.3732/ajb.91.9.1398.

Hardin, J.W. 1975. Hybridization and introgression in Quercus alba. Journal of the Arnold Arboretum 56: 336-363.

Hewitt, G.M. 1996. Some genetic consequences of ice ages, and their role in divergence and speciation. Biological Journal of the Linnean Society 58: 247-276. doi:10.1006/bijl.1996.0035.

Hipp, A.L. 2014. RADami: R Package for Phylogenetic Analysis of RADseq Data. R package version 1.0-3. Available from https://cran.rproject.org/web/packages/RADami/index.html [accessed 05 Jul 2016].

Hipp, A.L. 2015. Should hybridization make us skeptical of the oak phylogeny? International Oaks 26: 9-18. 
Hipp, A.L. and Weber, J.A. 2008. Taxonomy of Hill's oak (Quercus ellipsoidalis E.J. Hill): Evidence from AFLP data. Systematic Botany 33: 148-158.

Hipp, A.L., Eaton, D.A.R., Cavender-Bares, J., Fitzek, E., Nipper, R., and Manos, P.S. 2014. A framework phylogeny of the American oak clade based on sequenced RAD Data. PLoS ONE. 9(4): e93975. doi:10.1371/journal.pone.0093975.

Hollingsworth P.M., Li D.-Z., van der Bank M., and Twyford A.D. 2016. Telling plant species apart with DNA: from barcodes to genomes. Philosophical Transactions of the Royal Society B: Biological Sciences 371: 20150338. doi:10.1098/rstb.2015.0338.

Hubert, F., Grimm, G.W., Jousselin, E., Berry, V., Franc, A., and Kremer, A. 2014. Multiple nuclear genes stabilize the phylogenetic backbone of the genus Quercus. Systematics and Biodiversity 12(4): 405-423. doi:10.1080/14772000.2014.941037.

Katoh, K., and Standley, D.M. 2013. MAFFT multiple sequence alignment software version 7: Improvements in performance and usability. Molecular Biology and Evolution 30(4): 772780. doi:10.1093/molbev/mst010.

Kearse, M., Moir, R., Wilson, A., Stones-Havas, S., Cheung, M., Sturrock, S., Buxton, S., Cooper, A., Markowitz, S., Duran, C., Thierer, T., Ashton, B., Mentjies, P., and Drummond, A. 2012. Geneious Basic: an integrated and extendable desktop software platform for the organization and analysis of sequence data. Bioinformatics 28(12): 1647-1649.

Langmead, B., and Salzberg, S. 2012. Fast gapped-read alignment with Bowtie 2. Nature Methods 9: 357-359. 
Lynch, M. 2008. Estimation of nucleotide diversity, disequilibrium coefficients, and mutation rates from high-coverage genome-sequencing projects. Molecular Biology and Evolution 25(11): 2409-2419.

Maddison, W.P. 1997. Gene trees in species trees. Systematic Biology 46: 23-536. doi:10.1093/sysbio/46.3.523.

Manos, P.S., Doyle, J.J., and Nixon, K.C. 1999. Phylogeny, biogeography, and processes of molecular differentiation in Quercus subgenus Quercus (Fagaceae). Molecular Phylogenetics and Evolution 12(3): 333-349.

Mantel, N. 1967. The detection of disease clustering and a generalized regression approach. Cancer Research 27(2): 209-220.A

Morgan, M., Anders, S., Lawrence, M., Aboyoun, P., Pagès, H., and Gentleman, R. 2009. ShortRead: a Bioconductor package for input, quality assessment and exploration of highthroughput sequence data. Bioinformatics 25: 2607-2608.

Muir G., Fleming, C.C., and Schlötterer, C. 2000. Species status of hybridizing oaks. Nature (London) 405: 1016.

Muller, C.H. 1952. Ecological control of hybridization in Quercus: a factor in the mechanism of evolution. Evolution 6(2): 147-161.

Nixon, K.C., and Muller, C.H. 1997. Quercus Linnaeus sect. Quercus. In Flora of North America, Vol. 3. Edited by Flora of North America Editorial Committee. Oxford University Press, New York. pp. 471-506.

Oh, S.-H., and Manos, P.S. 2008. Molecular phylogenetics and cupule evolution in Fagaceae as inferred from nuclear CRABS CLAW sequences. Taxon 57: 434-451. 
Paradis, E., Claude, J., and Strimmer, K. 2004. APE: analyses of phylogenetics and evolution in R language. Bioinformatics 20: 289-290.

Parks, M. Cronn, R., and Liston, A. 2012. Separating the wheat from the chaff: mitigating the effects of noise in a plastome phylogenomic data set from Pinus L. (Pinaceae). BMC Evolutionary Biology 12:100. doi: 10.1186/1471-2148-12-100.

Pearse, I.S., and Hipp, A.L. 2009. Phylogenetic and trait similarity to a native species predict herbivory on non-native oaks. Proceedings of the National Academy of Sciences, U.S.A. 106(43): 18097-18102. doi:10.1073/pnas.0904867106.

Peñaloza-Ramírez J.M., González-Rodríguez, A., Mendoza-Cuenca, L., Caron, H., Kremer, A., and Oyama K. 2010. Interspecific gene flow in a multispecies oak hybrid zone in the Sierra Tarahumara of Mexico. Annals of Botany 105: 389-399. doi:10.1093/aob/mcp301.

Percy, D,., Argus, G.W., Cronk, Q.C., Fazekas, A.J., Kesanakurti, P.R., Burgess, K.S., Husband, B.C., Newmaster, S.G., Barrett, S.C.H., and Graham, S.W. 2014. Understanding the spectacular failure of DNA barcoding in willows (Salix): Does this result from a transspecific selective sweep? Molecular Ecology 23:4737-4756

Petit, R.J., and Excoffier, L. 2009. Gene flow and species delimitation. Trends in Ecology and Evolution 24(7): 386-393.

Petit, R.J., Wagner, D.B., and Kremer, A. 1993. Ribosomal DNA and chloroplast DNA polymorphisms in a mixed stand of Quercus robur and Q. petraea. Annals of Forest Science 50: $41 \mathrm{~s}-47 \mathrm{~s}$. 
Piredda, R., Simeone, M.C., Attimonelli, M., Bellarosa, R., and Schirone, B. 2010. Prospects of barcoding the Italian wild dendroflora: oaks reveal severe limitations to tracking species identity. Molecular Ecology Resources 11: 72-83.

R Core Team. 2016. R: A language and environment for statistical computing. R Foundation for Statistical Computing, Vienna, Austria. Available from https://www.R-project.org/ [accessed 19 October 2016].

Revell, L.J. 2012. phytools: An R package for phylogenetic comparative biology (and other things). Methods in Ecology and Evolution 3: 217-223. doi:10.1111/j.2041210X.2011.00169.

Rehfeldt, G. E., Crookston, N.L., Warwell, M.V., Evans, J.S. 2006. Empirical analyses of plantclimate relationships for the western United States. International Journal of Plant Sciences 167:1123-1150.

Rieseberg, L.H., Beckstrom Sternberg, S.M., Liston, A., and Arias, D.M. 1991. Phylogenetic and systematic inferences from chloroplast DNA and isozyme variation in Helianthus (Asteraceae). Systematic Botany 16:50-76.

Rieseberg, L.H., and Soltis, D.E. 1991. Phylogenetic consequences of cytoplasmic gene flow in plants. Evolutionary Trends in Plants 5(1): 65-84.

Roberts, D.R. and Hamann, A. 2012. Predicting potential climate change impacts with bioclimate envelope models: a palaeoecological perspective. Global Ecology and Biogeography 21:121-133. 
Roberts, D.R. and Hamann, A. 2015. Glacial refugia and modern genetic diversity of 22 western North American tree species. Proceedings of the Royal Society B: Biological Sciences 282: 2903. doi:10.1098/rspb.2014.2903.

Rognes, T., Flouri, T., Nichols, B., Quince, C., and Mahé, F. 2016. VSEARCH: a versatile open source tool for metagenomics. PeerJ Preprints 4: e2409v1. Available from https://doi.org/10.7287/peerj.preprints.2409v1 [accessed 19 October 2016].

Ruhfel, B.R., Gitzendanner, M.A., Soltis, P.S., Soltis, D.E., and Burleigh, J.G. 2014. From algae to angiosperms-inferring the phylogeny of green plants (Viridiplantae) from 360 plastid genomes. BMC Evolutionary Biology 14: 23. doi:10.1186/1471-2148-14-23.

Sang, T., Crawford, D.J., and Stuessy, T.F. 1997. Chloroplast DNA phylogeny, reticulate evolution, and biogography of Paeonia (Paeoniaceae). American Journal of Botany 84: $1120-1136$.

Schroeder, H., Cronn, R., Yanbaev, Y., Jennings, T., Mader, M., Degen, B., and Kersten, B. 2016. Development of molecular markers for determining continental origin of wood from white oaks (Quercus L. sect. Quercus). PLoS ONE 11(6): e0158221. doi:10.1371/journal.pone.0158221.

Shaw, J., Craddock, J.H., and Binkley, M.A. 2012. Phylogeny and phylogeography of North American Castanea Mill. (Fagaceae) using cpDNA suggests gene sharing in the southern Appalachians (Castanea Mill., Fagaceae). Castanea 77(2): 186-211. doi:10.2179/11-033.

Shaw, J., Shafer, H.L., Leonard, O.R., Kovach, M.J., Schorr, M., and Morris, A.B. 2014. Chloroplast DNA sequence utility for the lowest phylogenetic and phylogeographic 
inferences in angiosperms: the tortoise and the hare IV. American Journal of Botany 101(11): 1987-2004. doi:10.3732/ajb.1400398.1993.

Simeone, M.C., Piredda, R., Papini, A., Vessella, F. and Schirone, B. 2012. Application of plastid and nuclear markers to DNA barcoding of Euro-Mediterranean oaks (Quercus, Fagaceae): Problems, prospects and phylogenetic implications. Botanical Journal of the Linnean Society 172:478-499. doi:10.1111/boj.12059.

Simeone, M.C., Grimm, G.W., Papini, A., Vessella, F., Cardoni, S., Tordoni, E., Piredda, R., Franc, A., and Denk, T. 2016. Plastome data reveal multiple geographic origins of Quercus Group Ilex. PeerJ 4: e1897. doi:10.7717/peerj.1897.

Smouse, P.E., Long, J.C., and Sokal, R.R. 1986. Multiple regression and correlation extensions of the Mantel test of matrix correspondence. Systematic Zoology 35(4): 627-632.

Soltis, D.E., Morris, A.B., McLachlan, J.S., Manos, P.S., and Soltis, P.S. 2006. Comparative phylogeography of unglaciated eastern North America. Molecular Ecology 15: 4261-4293. doi:10.1111/j.1365-294X.2006.03061.x.

Sork, V.L., Riordin, E., Gugger, P.F., Fitz-Gibbon, S., Wei, X., and Ortego, J. 2016. Phylogeny and introgression of California scrub white oaks (Quercus section Quercus). International Oaks 27: 61-74.

Stamatakis, A. 2014. RAxML Version 8: A tool for phylogenetic analysis and post-analysis of large phylogenies. Bioinformatics 30(9): 1312-1313. doi:10.1093/bioinformatics/btu033. 
Taberlet, P., Fumagalli, L., Wust-Saucy, A.-G., and Cosson, J.-F. 1998. Comparative phylogeography and postglacial colonization routes in Europe. Molecular Ecology 7:453464. doi:10.1046/j.1365-294x.1998.00289.x.

U.S. Department of Justice. Statement of facts, United States of American v. Lumber Liquidators. Case document 2:15-cr-00126-RAJ-LRL (2015). Available online: http://www.justice.gov/opa/file/787141/download.

Van Valen, L. 1976. Ecological species, multispecies, and oaks. Taxon 25: 233-239.

Via, S., and West, J. 2008. The genetic mosaic suggests a new role for hitchhiking in ecological speciation. Molecular Ecology 17(19): 4334-4345.

Wendel, J.F., and Doyle, J.1998. Phylogenetic incongruence: Window into genome history and molecular evolution. In: Soltis, D., Soltis, P., Doyle, J., editors. Molecular Systematics of Plants II: DNA sequencing. Kluwer, Boston, USA. pp. 265-296.

Whittemore, A.T., and Schaal, B.A. 1991. Interspecific gene flow in sympatric oaks. Proceedings of the National Academy of Sciences, U.S.A. 88: 2540-2544.

Wiegand, K.M. 1935. A taxonomist's experience with hybrids in the wild. Science 81: 161-166. 
Table 1. Samples metadata. SRA BioSample ID references NCBI sample ID for each sequence.

\begin{tabular}{|c|c|c|c|c|c|c|c|c|c|c|}
\hline $\begin{array}{l}\text { Specimen } \\
\text { code }\end{array}$ & Species & $\frac{\text { Herbarium }}{\text { accession }}$ & Latitude & Longitude & Section & Continent & Country & State/Province & $\frac{\text { RADseq SRA }}{\text { BioSample ID }}$ & $\begin{array}{l}\text { cpDNA SRA } \\
\text { BioSample ID }\end{array}$ \\
\hline OAK-MOR-359 & Quercus alba L. & 174462 & 45.367983 & -93.219304 & Q & NA & USA & Minnesota & SAMN06446142 & SAMN03264816 \\
\hline PM-19 & Quercus alba L. & 177669 & 36.021818 & -79.016068 & Q & NA & USA & North Carolina & SAMN06446143 & \\
\hline OAK-MOR-204 & Quercus alba L. & 175336 & 39.9347718 & -89.8016103 & Q & NA & USA & Illinois & SAMN06446144 & \\
\hline OAK-MOR-76 & Quercus alba L. & 174513 & 31.866545 & -86.349921 & Q & NA & USA & Michigan & SAMN06446145 & \\
\hline QUAL_NC_2 & Quercus alba L. & & 35.25357 & -82.19709 & Q & NA & USA & NC & & SAMN03264817 \\
\hline QUAL_PN_1 & Quercus alba L. & & 41.38389 & -79.054 & Q & NA & USA & PN & & SAMN03264818 \\
\hline QUAL_PN_4 & Quercus alba L. & & 41.50643 & -79.24511 & Q & NA & USA & PN & & SAMN03264819 \\
\hline OAK-MOR-413 & Quercus arizonica Sarg. & 174229 & 31.44959506 & -109.2431153 & Q & NA & USA & Arizona & SAMN06446146 & SAMN03264796 \\
\hline OAK-MOR-508 & $\begin{array}{l}\text { Quercus berberidifolia } \\
\text { Liebm. }\end{array}$ & 174692 & 38.41167 & -122.04917 & Q & NA & USA & California & SAMN06446147 & SAMN03264799 \\
\hline OAK-MOR-342 & Quercus bicolor Willd. & 174534 & 41.740864 & -87.860335 & Q & NA & USA & Illinois & SAMN06446148 & SAMN03264820 \\
\hline OAK-MOR-289 & Quercus bicolor Willd. & 175338 & 38.9048 & -94.8926 & Q & NA & USA & Illinois & SAMN06446149 & SAMN03264821 \\
\hline OAK-MOR-436 & $\begin{array}{l}\text { Quercus boyntonii } \\
\text { Beadle }\end{array}$ & 175278 & 34.014264 & -86.00664 & Q & NA & USA & Alabama & SAMN06446150 & SAMN03264814 \\
\hline OAK-MOR-415 & $\begin{array}{l}\text { Quercus chrysolepis } \\
\text { Liebm. }\end{array}$ & 174230 & 31.43347498 & $3-109.2431153$ & $P$ & NA & USA & Arizona & SAMN06446151 & SAMN03264797 \\
\hline OAK-MOR-474 & $\begin{array}{l}\text { Quercus chrysolepis } \\
\text { Liebm. }\end{array}$ & 174682 & 38.757996 & -120.548892 & $P$ & NA & USA & California & SAMN06446152 & SAMN03264807 \\
\hline Qd_01 & Quercus dentata Thunb. & & 42.801233 & 131.245433 & Q & EU & RUS & & & SAMN03653768 \\
\hline Qd_03 & Quercus dentata Thunb. & & 42.801267 & 131.245467 & Q & EU & RUS & & & SAMN03653764 \\
\hline Qd_04 & Quercus dentata Thunb. & & 42.801283 & 131.245483 & Q & EU & RUS & & & SAMN03653765 \\
\hline Qd_05 & Quercus dentata Thunb. & & 42.8013 & 131.2455 & Q & EU & RUS & & & SAMN03653766 \\
\hline Qd_06 & Quercus dentata Thunb. & & 42.801317 & 131.245517 & Q & EU & RUS & & & SAMN03653769 \\
\hline Qd_09 & Quercus dentata Thunb. & & 42.801367 & 131.245567 & Q & EU & RUS & & & SAMN03653767 \\
\hline Qd_10 & Quercus dentata Thunb. & & 42.801383 & 131.245583 & Q & EU & RUS & & & SAMN03653762 \\
\hline OAK-MOR-531 & $\begin{array}{l}\text { Quercus douglasii Hook. } \\
\text { \& Arn. }\end{array}$ & 174681 & 38.696153 & -120.887322 & Q & NA & USA & California & SAMN06446153 & SAMN03264808 \\
\hline OAK-MOR-406 & $\begin{array}{l}\text { Quercus engelmannii } \\
\text { Greene }\end{array}$ & 174583 & 32.594883 & -116.843812 & Q & NA & USA & California & SAMN06446154 & SAMN03264801 \\
\hline OAK-MOR-387 & Quercus gambelii Nutt. & 174463 & 38.861158 & -105.172682 & Q & NA & USA & Colorado & SAMN06446155 & SAMN03264809 \\
\hline OAK-MOR-546 & Quercus gambelii Nutt. & 174218 & 31.75663448 & $3-109.2431153$ & Q & NA & USA & Arizona & SAMN06446156 & SAMN03264795 \\
\hline QUGA4_OR_1 & $\begin{array}{l}\text { Quercus garryana } \\
\text { Douglas ex. Hook. }\end{array}$ & & 43.3050 & -123.2412 & Q & NA & USA & OR & & SAMN03264824 \\
\hline OAK-MOR-422 & $\begin{array}{l}\text { Quercus garryana } \\
\text { Douglas ex. Hook. }\end{array}$ & 174699 & 38.678479 & -120.812513 & Q & NA & USA & California & SAMN06446157 & SAMN03264823 \\
\hline OAK-MOR-123 & Quercus lobata Née & 174703 & 36.61667 & -120.85 & Q & NA & USA & California & SAMN06446158 & SAMN03264805 \\
\hline OAK-MOR-385 & Quercus lyrata Walter & 174540 & 36.720972 & -90.112917 & Q & NA & USA & Missouri & SAMN06446159 & SAMN03264826 \\
\hline OAK-MOR-611 & Quercus lyrata Walter & 174529 & 30.7084 & -84.8564 & Q & NA & USA & Georgia & SAMN06446160 & SAMN03264825 \\
\hline
\end{tabular}




\begin{tabular}{|c|c|c|c|c|c|c|c|c|c|c|}
\hline OAK-MOR-356 & $\begin{array}{l}\text { Quercus macrocarpa } \\
\text { Michx. }\end{array}$ & 174544 & 37.149225 & -94.443003 & Q & NA & USA & Missouri & SAMN06446161 & \\
\hline OAK-MOR-357 & $\begin{array}{l}\text { Quercus macrocarpa } \\
\text { Michx. }\end{array}$ & $174520 / 174521$ & 141.486798 & -87.799832 & Q & NA & USA & Illinois & SAMN06446162 & \\
\hline OAK-MOR-673 & $\begin{array}{l}\text { Quercus macrocarpa } \\
\text { Michx. }\end{array}$ & 175524 & 45.5129 & -73.5506 & Q & NA & CAN & Quebec & SAMN06446163 & SAMN03264829 \\
\hline OAK-MOR-672 & $\begin{array}{l}\text { Quercus macrocarpa } \\
\text { Michx. }\end{array}$ & 175314 & 43.6 & -105.4 & Q & NA & USA & New Mexico & SAMN06446164 & SAMN03264812 \\
\hline QUMA2_KS_1 & $\begin{array}{l}\text { Quercus macrocarpa } \\
\text { Michx. }\end{array}$ & & 39.0286 & -94.9404 & Q & NA & USA & KS & & SAMN03264827 \\
\hline QUMA2_WI_3 & $\begin{array}{l}\text { Quercus macrocarpa } \\
\text { Michx. }\end{array}$ & & 42.8751 & -88.3276 & Q & NA & USA & WI & & SAMN03264830 \\
\hline OAK-MOR-420 & $\begin{array}{l}\text { Quercus margarettae } \\
\text { (Ashe) Small }\end{array}$ & 174705 & 29.616474 & -97.572742 & Q & NA & USA & Texas & SAMN06446165 & SAMN03264804 \\
\hline OAK-MOR-353 & Quercus michauxii Nutt. & 174516 & 36.644722 & -89.285 & Q & NA & USA & Missouri & SAMN06446166 & SAMN03264833 \\
\hline OAK-MOR-694 & Quercus michauxii Nutt. & 174537 & 738.905693 & -86.035881 & $Q$ & NA & USA & Indiana & SAMN06446167 & SAMN03264832 \\
\hline OAK-MOR-700 & Quercus michauxii Nutt. & 175231 & 137.15382 & -89.34699 & Q & NA & USA & Illinois & SAMN06446168 & SAMN03264831 \\
\hline PM143 & Quercus michauxii Nutt. & & 35.99555 & -79.05416 & Q & NA & USA & North Carolina & SAMN06446169 & \\
\hline PM155 & Quercus michauxii Nutt. & & 36.015223 & -78.923317 & Q & NA & USA & North Carolina & SAMN06446170 & \\
\hline OAK-MOR-125 & $\begin{array}{l}\text { Quercus mohriana } \\
\text { Buckley ex Rydb. }\end{array}$ & 174704 & 31.979167 & -104.754722 & Q & NA & USA & Texas & SAMN06446171 & SAMN03264800 \\
\hline OAK-MOR-360 & $\begin{array}{l}\text { Quercus mongolica } \\
\text { Fisch. ex Ledeb. }\end{array}$ & 174518 & 340.58 & 116.7375 & Q & EU & $\mathrm{CHI}$ & Beijing Shi & SAMN06446172 & SAMN03264834 \\
\hline Opb_13 & $\begin{array}{l}\text { Quercus mongolica } \\
\text { Fisch. ex Ledeb. }\end{array}$ & & 50.187167 & 138.591 & Q & EU & RUS & & & SAMN03653770 \\
\hline Opb_21 & $\begin{array}{l}\text { Quercus mongolica } \\
\text { Fisch. ex Ledeb. }\end{array}$ & & 50.187167 & 138.591 & Q & EU & RUS & & & SAMN03653771 \\
\hline Opb_26 & $\begin{array}{l}\text { Quercus mongolica } \\
\text { Fisch. ex Ledeb. }\end{array}$ & & 50.187167 & 138.591 & Q & EU & RUS & & & SAMN03653772 \\
\hline Opl_19 & $\begin{array}{l}\text { Quercus mongolica } \\
\text { Fisch. ex Ledeb. }\end{array}$ & & 43.374833 & 133.892 & Q & EU & RUS & & & SAMN03653773 \\
\hline Opl_20 & $\begin{array}{l}\text { Quercus mongolica } \\
\text { Fisch. ex Ledeb. }\end{array}$ & & 43.374833 & 133.892 & $Q$ & EU & RUS & & & SAMN03653774 \\
\hline Opl_21 & $\begin{array}{l}\text { Quercus mongolica } \\
\text { Fisch. ex Ledeb. }\end{array}$ & & 43.374833 & 133.892 & Q & EU & RUS & & & SAMN03653775 \\
\hline Oto_03 & $\begin{array}{l}\text { Quercus mongolica } \\
\text { Fisch. ex Ledeb. }\end{array}$ & & 49.0497 & 131.860333 & Q & EU & RUS & & & SAMN03653777 \\
\hline Oto_14 & $\begin{array}{l}\text { Quercus mongolica } \\
\text { Fisch. ex Ledeb. }\end{array}$ & & 49.0497 & 131.860333 & Q & EU & RUS & & & SAMN03653776 \\
\hline Ovl_02 & $\begin{array}{l}\text { Quercus mongolica } \\
\text { Fisch. ex Ledeb. }\end{array}$ & & 43.073167 & 131.909833 & $Q$ & EU & RUS & & & SAMN03653779 \\
\hline Ovl_04 & $\begin{array}{l}\text { Quercus mongolica } \\
\text { Fisch. ex Ledeb. }\end{array}$ & & 43.073167 & 131.909833 & Q & EU & RUS & & & SAMN03653780 \\
\hline Ovl_14 & $\begin{array}{l}\text { Quercus mongolica } \\
\text { Fisch. ex Ledeb. }\end{array}$ & & 43.073167 & 131.909833 & $Q$ & EU & RUS & & & SAMN03653778 \\
\hline Qkor_02 & $\begin{array}{l}\text { Quercus mongolica } \\
\text { Fisch. ex Ledeb. }\end{array}$ & & 37.5667 & 126.9781 & $Q$ & EU & SKO & & & SAMN03653781 \\
\hline Qkor_07 & $\begin{array}{l}\text { Quercus mongolica } \\
\text { Fisch. ex Ledeb. }\end{array}$ & & 37.5667 & 126.9781 & Q & EU & SKO & & & SAMN03653782 \\
\hline Qkor_08 & $\begin{array}{l}\text { Quercus mongolica } \\
\text { Fisch. ex Ledeb. }\end{array}$ & & & & Q & EU & SKO & & & SAMN03653803 \\
\hline Qm_14 & $\begin{array}{l}\text { Quercus mongolica } \\
\text { Fisch. ex Ledeb. }\end{array}$ & & 45.083333 & 133.947194 & Q & EU & RUS & & & SAMN03653784 \\
\hline Qm_18 & $\begin{array}{l}\text { Quercus mongolica } \\
\text { Fisch. ex Ledeb. }\end{array}$ & & 46.083028 & 133.945889 & $Q$ & EU & RUS & & & SAMN03653785 \\
\hline Qm_20 & $\begin{array}{l}\text { Quercus mongolica } \\
\text { Fisch. ex Ledeb. }\end{array}$ & & 46.082194 & 133.945556 & $Q$ & EU & RUS & & & SAMN03653786 \\
\hline Qm_42 & $\begin{array}{l}\text { Quercus mongolica } \\
\text { Fisch. ex Ledeb. }\end{array}$ & & 45.429692 & 127.092031 & $Q$ & EU & $\mathrm{CHI}$ & & & SAMN03653800 \\
\hline Qm_44 & $\begin{array}{l}\text { Quercus mongolica } \\
\text { Fisch. ex Ledeb. }\end{array}$ & & 45.429531 & 127.091156 & Q & EU & $\mathrm{CHI}$ & & & SAMN03653801 \\
\hline
\end{tabular}




\begin{tabular}{|c|c|c|c|c|c|c|c|c|c|c|}
\hline Qm_49 & $\begin{array}{l}\text { Quercus mongolica } \\
\text { Fisch. ex Ledeb. }\end{array}$ & & 45.428283 & 127.090569 & Q & EU & $\mathrm{CHI}$ & & & SAMN03653802 \\
\hline Qm_65 & $\begin{array}{l}\text { Quercus mongolica } \\
\text { Fisch. ex Ledeb. }\end{array}$ & & 48.619717 & 135.90783 & Q & EU & RUS & & & SAMN03653787 \\
\hline Qm_68 & $\begin{array}{l}\text { Quercus mongolica } \\
\text { Fisch. ex Ledeb. }\end{array}$ & & 48.619717 & 135.90783 & Q & EU & RUS & & & SAMN03653788 \\
\hline Qm_71 & $\begin{array}{l}\text { Quercus mongolica } \\
\text { Fisch. ex Ledeb. }\end{array}$ & & 48.619717 & 135.90783 & Q & EU & RUS & & & SAMN03653789 \\
\hline Qm_SUW_4 & $\begin{array}{l}\text { Quercus mongolica } \\
\text { Fisch. ex Ledeb. }\end{array}$ & & 37.5667 & 126.9781 & Q & EU & SKO & & & SAMN03653783 \\
\hline OAK-MOR-352 & Quercus montana Willd. & 1748463 & 37.141444 & -79.995722 & Q & NA & USA & Virginia & SAMN06446173 & SAMN03264838 \\
\hline OAK-MOR-693 & Quercus montana Willd. & 1745143 & 37.52575 & -80.249722 & Q & NA & USA & Virginia & SAMN06446174 & \\
\hline OAK-MOR-575 & Quercus montana Willd. & 175353 & 35.429102 & -82.251822 & Q & NA & USA & North Carolina & SAMN06446175 & \\
\hline OAK-MOR-383 & $\begin{array}{l}\text { Quercus muehlenbergii } \\
\text { Engelm. }\end{array}$ & 174533 & 41.210569 & -88.017575 & Q & NA & USA & Illinois & SAMN06446176 & SAMN03264810 \\
\hline OAK-MOR-632 & $\begin{array}{l}\text { Quercus muehlenbergii } \\
\text { Engelm. }\end{array}$ & 1753453 & 35.623899 & -99.008733 & Q & NA & USA & Oklahoma & SAMN06446177 & SAMN03264815 \\
\hline OAK-MOR-639 & $\begin{array}{l}\text { Quercus muehlenbergii } \\
\text { Engelm. }\end{array}$ & 1746903 & 31.97917 & -104.75417 & Q & NA & USA & Texas & SAMN06446178 & SAMN03264803 \\
\hline OAK-MOR-520 & $\begin{array}{l}\text { Quercus petraea (Matt.) } \\
\text { Liebl. }\end{array}$ & 174539 & 51.816667 & 19.883333 & Q & EU & POL & & SAMN06446179 & SAMN03264835 \\
\hline HB_175 & $\begin{array}{l}\text { Quercus petraea (Matt.) } \\
\text { Liebl. }\end{array}$ & & 53.700539 & 10.719256 & Q & EU & GER & & & SAMN03653790 \\
\hline HB_181 & $\begin{array}{l}\text { Quercus petraea (Matt.) } \\
\text { Liebl. }\end{array}$ & & 53.700539 & 10.719256 & Q & EU & GER & & & SAMN03653791 \\
\hline MST_29 & $\begin{array}{l}\text { Quercus petraea (Matt.) } \\
\text { Liebl. }\end{array}$ & & 51.909356 & 7.740925 & Q & EU & GER & & & SAMN03653792 \\
\hline MST_30 & $\begin{array}{l}\text { Quercus petraea (Matt.) } \\
\text { Liebl. }\end{array}$ & & 51.909356 & 7.740925 & Q & EU & GER & & & SAMN03653793 \\
\hline MST_31 & $\begin{array}{l}\text { Quercus petraea (Matt.) } \\
\text { Liebl. }\end{array}$ & & 51.909356 & 7.740925 & Q & EU & GER & & & SAMN03653794 \\
\hline OAK-MOR-532 & Quercus prinoides Willd. & 175238 & 40.076297 & -95.720956 & Q & NA & USA & Nebraska & SAMN06446180 & SAMN03264811 \\
\hline QUPR2_NC_1 & Quercus prinoides Willd. & & 35.2535 & -82.197 & Q & NA & USA & NC & & SAMN03264836 \\
\hline QUPR2_PN_1 & Quercus prinoides Willd. & & 41.5073 & -79.2442 & Q & NA & USA & PN & & SAMN03264837 \\
\hline OAK-MOR-392 & Quercus robur L. & 174567 & 55.838647 & 37.600483 & Q & EU & RUS & & SAMN06446181 & SAMN03264839 \\
\hline ARK_15 & Quercus robur L. & & 54.416667 & 56.666667 & Q & EU & RUS & & & SAMN03653809 \\
\hline B2_01 & Quercus robur L. & & 52.674197 & 58.742517 & Q & EU & RUS & & & SAMN03653795 \\
\hline PIE_06 & Quercus robur L. & & 44.737028 & -0.776389 & Q & EU & FRA & & & SAMN03653797 \\
\hline PIE_10 & Quercus robur L. & & 44.737028 & -0.776389 & Q & EU & FRA & & & SAMN03653796 \\
\hline SVT_06 & Quercus robur L. & & 49.052833 & 37.9295 & Q & EU & UKR & & & SAMN03653807 \\
\hline SVT_11 & Quercus robur L. & & 49.052833 & 37.9295 & Q & EU & UKR & & & SAMN03653808 \\
\hline TAM_01 & Quercus robur L. & & 59.974439 & 23.435525 & Q & EU & FIN & & & SAMN03653798 \\
\hline TAM_10 & Quercus robur L. & & 59.974439 & 23.435525 & Q & EU & FIN & & & SAMN03653799 \\
\hline WR4_01 & Quercus robur L. & & 53.685833 & 23.792833 & Q & EU & BEL & & & SAMN03653805 \\
\hline WR4_07 & Quercus robur L. & & 53.685833 & 23.792833 & Q & EU & BEL & & & SAMN03653806 \\
\hline OAK-MOR-498 & Quercus rubra L. & 174465 & & & L & NA & USA & Illinois & SAMN06446182 & \\
\hline OAK-MOR-388 & $\begin{array}{l}\text { Quercus stellata } \\
\text { Wangenh. }\end{array}$ & 174535 & 40.5849 & -91.2756 & Q & NA & USA & lowa & SAMN06446183 & SAMN03264841 \\
\hline
\end{tabular}




\begin{tabular}{|c|c|c|c|c|c|c|c|c|c|c|}
\hline OAK-MOR-340 & $\begin{array}{l}\text { Quercus stellata } \\
\text { Wangenh. }\end{array}$ & 174543 & 38.034944 & -91.520306 & Q & NA & USA & Missouri & SAMN06446184 & \\
\hline OAK-MOR-616 & $\begin{array}{l}\text { Quercus stellata } \\
\text { Wangenh. }\end{array}$ & 175244 & 35.4 & -82.4 & Q & NA & USA & North Carolina & SAMN06446185 & SAMN03264813 \\
\hline QUST_GA_2 & $\begin{array}{l}\text { Quercus stellata } \\
\text { Wangenh. }\end{array}$ & & 33.9025 & -83.3824 & Q & NA & USA & GA & & SAMN03264840 \\
\hline OAK-MOR-133 & $\begin{array}{l}\text { Quercus tomentella } \\
\text { Engelm. }\end{array}$ & 174688 & 34.023206 & -119.765766 & $\mathrm{P}$ & NA & USA & California & SAMN06446186 & SAMN03264802 \\
\hline OAK-MOR-377 & $\begin{array}{l}\text { Quercus vacciniifolia } \\
\text { Kellogg }\end{array}$ & 174684 & 38.811462 & -120.123212 & $P$ & NA & USA & California & SAMN06446187 & SAMN03264806 \\
\hline OAK-MOR-397 & $\begin{array}{l}\text { Quercus vaseyana } \\
\text { Buckley }\end{array}$ & 174580 & 29.970985 & -101.109021 & Q & NA & USA & Texas & SAMN06446188 & SAMN03264798 \\
\hline
\end{tabular}


Table 2. Partial regressions of plastome variation on nuclear phylogeny and geographic distance, using Mantel permutations to assess significance.

\begin{tabular}{|c|c|c|c|c|c|c|}
\hline Dataset & plast $\sim$ nuc+geo & plast $\sim$ nuc.geo & plast $\sim$ geo.nuc & plast $\sim g e o$ & plast $\sim$ nuc & nuc geo \\
\hline (1) All oaks sampled & $\mathrm{r} 2=0.596$ & $\begin{aligned} r 2 & =0.382 \\
p & <0.002\end{aligned}$ & $\begin{aligned} r 2 & =0.413 \\
p & <0.002\end{aligned}$ & $\begin{aligned} r 2 & =0.346, \\
p & <0.002\end{aligned}$ & $\begin{aligned} r 2 & =0.311 \\
p & <0.002\end{aligned}$ & $\begin{aligned} \mathrm{r} 2 & =0.011 \\
\mathrm{p} & =0.460\end{aligned}$ \\
\hline $\begin{array}{l}\text { (2) North American } \\
\text { oaks }\end{array}$ & $\mathrm{r} 2=0.464$ & $\begin{aligned} r 2 & =0.407 \\
p & <0.002\end{aligned}$ & $\begin{aligned} r 2 & =0.028 \\
p & =0.062\end{aligned}$ & $\begin{aligned} r 2 & =0.097 \\
p & <0.002\end{aligned}$ & $\begin{aligned} & r 2=0.449 \\
& p<0.002\end{aligned}$ & $\begin{aligned} r 2 & =0.084 \\
p & <0.002\end{aligned}$ \\
\hline $\begin{array}{l}\text { (3) North American } \\
\text { white oaks }\end{array}$ & $\mathrm{r} 2=0.116$ & $\begin{aligned} r 2 & =0.001 \\
p & =0.621\end{aligned}$ & $\begin{aligned} r 2 & =0.112 \\
p & <0.002\end{aligned}$ & $\begin{aligned} r 2 & =0.115 \\
p & <0.002\end{aligned}$ & $\begin{aligned} r 2 & =0.004, p \\
& =0.517\end{aligned}$ & $\begin{aligned} r 2 & =0.077 \\
p & <0.002\end{aligned}$ \\
\hline $\begin{array}{l}\text { (4) North American } \\
\text { oaks without } \\
\text { California }\end{array}$ & r2 $=0.526$ & $\begin{aligned} r 2 & =0.301 \\
p & <0.002\end{aligned}$ & $\begin{aligned} r 2 & =0.162 \\
p & <0.002\end{aligned}$ & $\begin{aligned} r 2 & =0.322, \\
p & <0.002\end{aligned}$ & $\begin{aligned} r 2 & =0.435 \\
p & <0.002\end{aligned}$ & $\begin{aligned} r 2 & =0.204, \\
p & <0.002\end{aligned}$ \\
\hline $\begin{array}{l}\text { (5) Eastern North } \\
\text { American white } \\
\text { oaks }\end{array}$ & $\mathrm{r} 2=0.013$ & $\begin{aligned} r 2 & =0.011 \\
p & =0.188\end{aligned}$ & $\begin{aligned} r 2 & =0.003 \\
p & =0.779\end{aligned}$ & $\begin{aligned} r 2 & =0.002, \\
p & =0.817\end{aligned}$ & $\begin{aligned} R 2 & =0.011, p \\
& =0.156\end{aligned}$ & $\begin{aligned} r 2 & =0.002, \\
p & =0.588\end{aligned}$ \\
\hline
\end{tabular}

Note: Models tested are represented using to indicate "is predicted by" and "." to indicate partial regression, where the predictor before the "." is the partial coefficient being estimated, and the predictor after the "." is the covariate. Abbreviations: Plast = the plastome phylogenetic pairwise distances; nuc $=$ nuclear $($ RADseq $)$ phylogeny pairwise distances; geo = geographic (great circle) pairwise distances. Shaded cells are significant at $\mathrm{p}<0.002$. 


\section{FIGURE CAPTIONS}

Figure 1. Plastome phylogeny, all samples. Maximum likelihood phylogeny with nonparametric bootstrap values indicated by branch thickness (thickest branches: bootstrap $>90 \%$; medium thickness: bootstrap $\leq 90 \%,>50 \%$; thinnest branches: bootstrap $\leq 50 \%$ ). Colored blocks indicate the four main plastome lineages. Sample names follow Table 1.

Figure 2. Nuclear RADseq phylogeny (left panel) and plastome phylogeny (right panel), containing all samples listed in Table 1. Corresponding tips are connected between trees. Bootstrap values are shown in boxes at the nodes of the clades to which they correspond. Tips are color-coded by clade; intermediate oaks are blue, california white oaks are red, and all other white oaks are black.

Figure 3. Plastome phylogeny, all samples except outgroup, mapped to sample locations. Maximum likelihood plastome phylogeny (see Fig. 1), excluding the Quercus rubra outgroup. Colored blocks correspond to lineages in Fig. 1. 


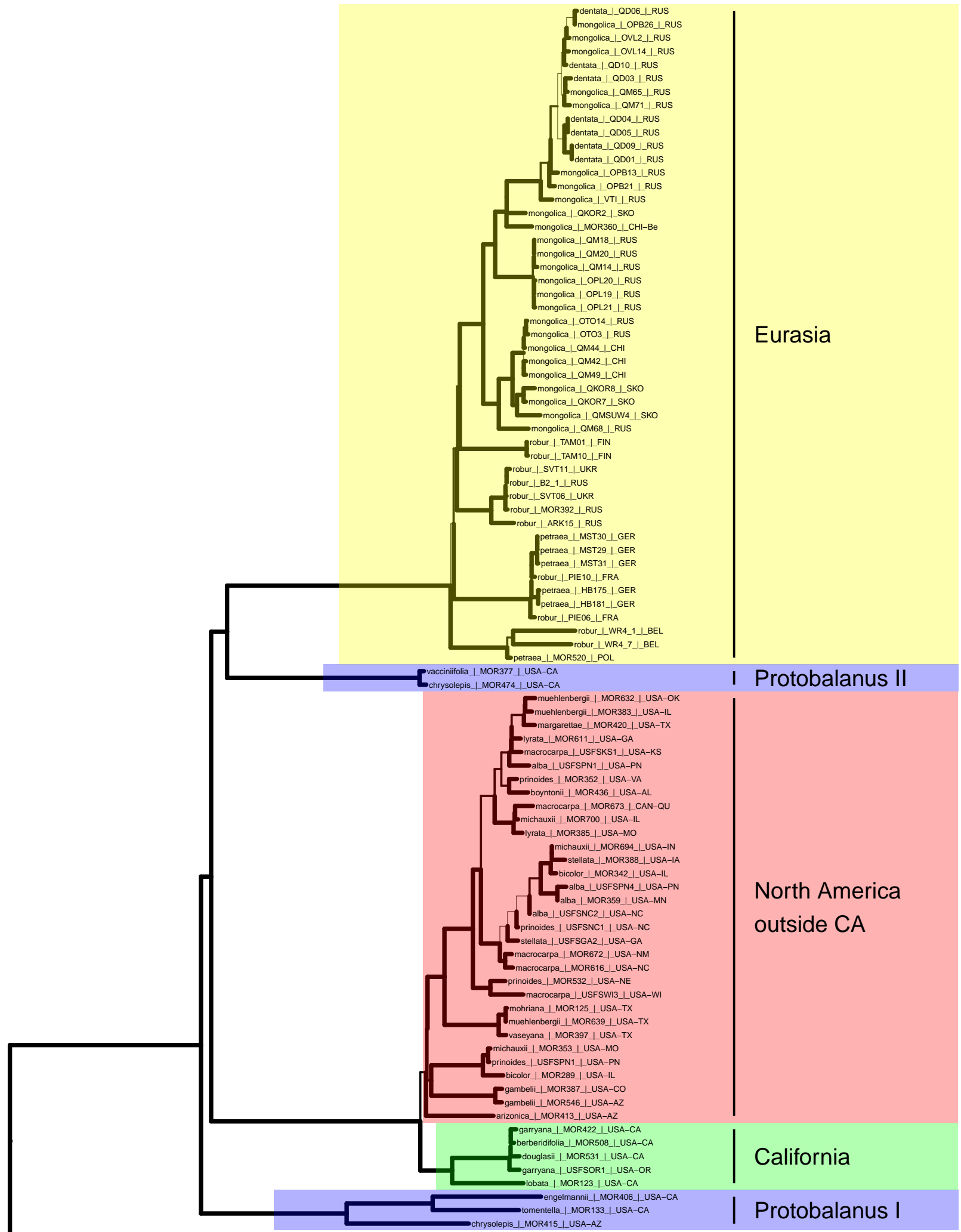




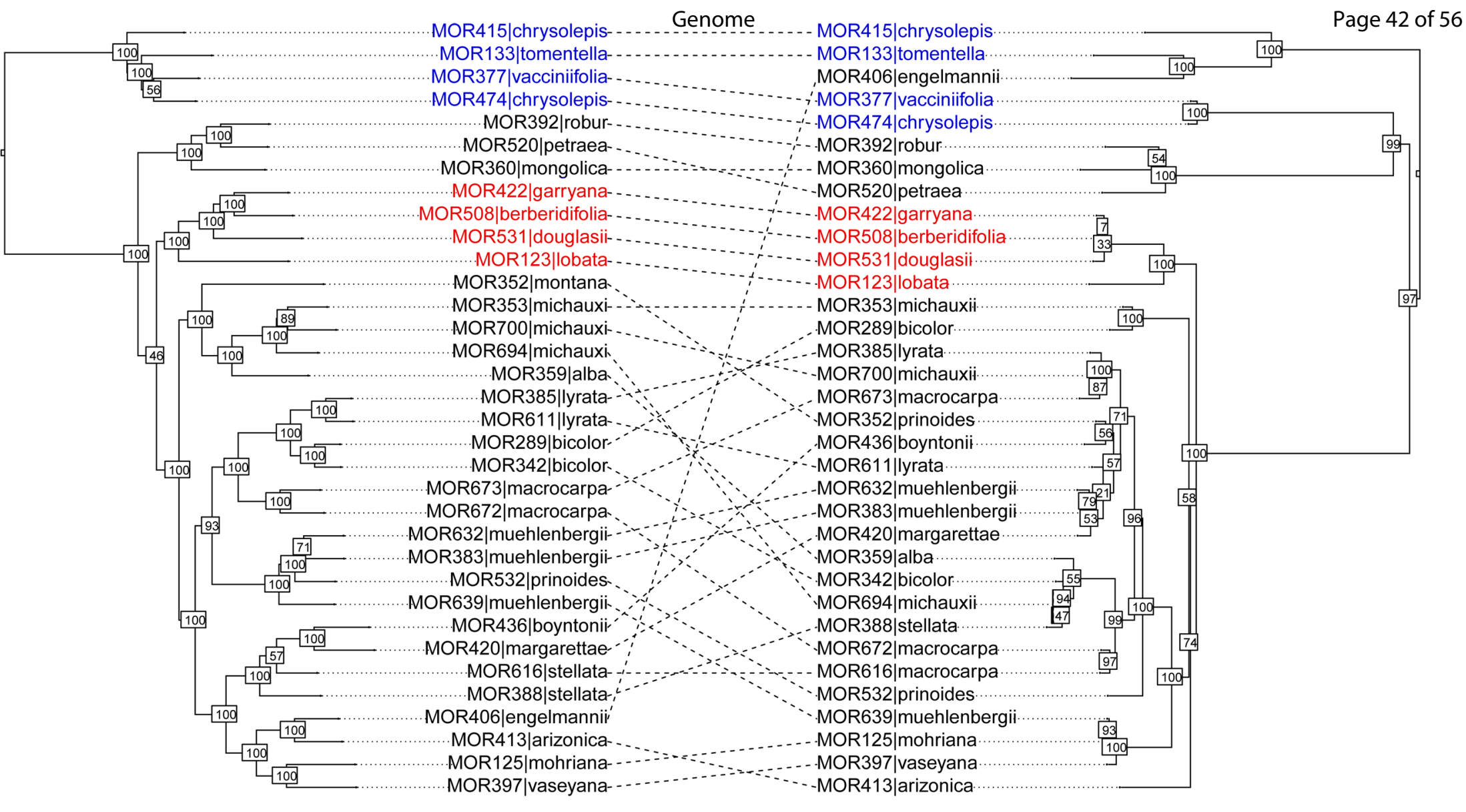

RADsêtas://mc06.manuscriptcentral.com/genome Plylasstome 


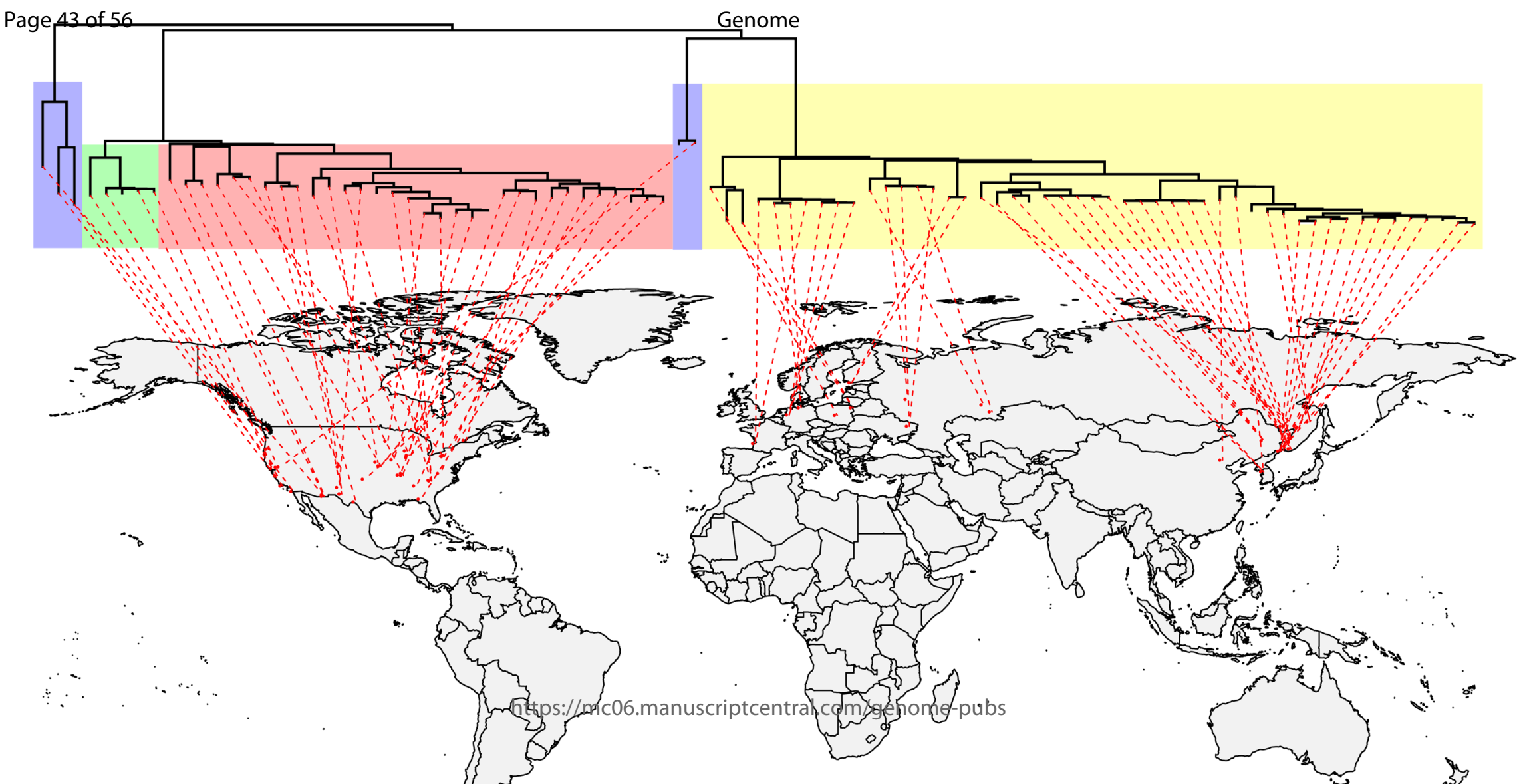




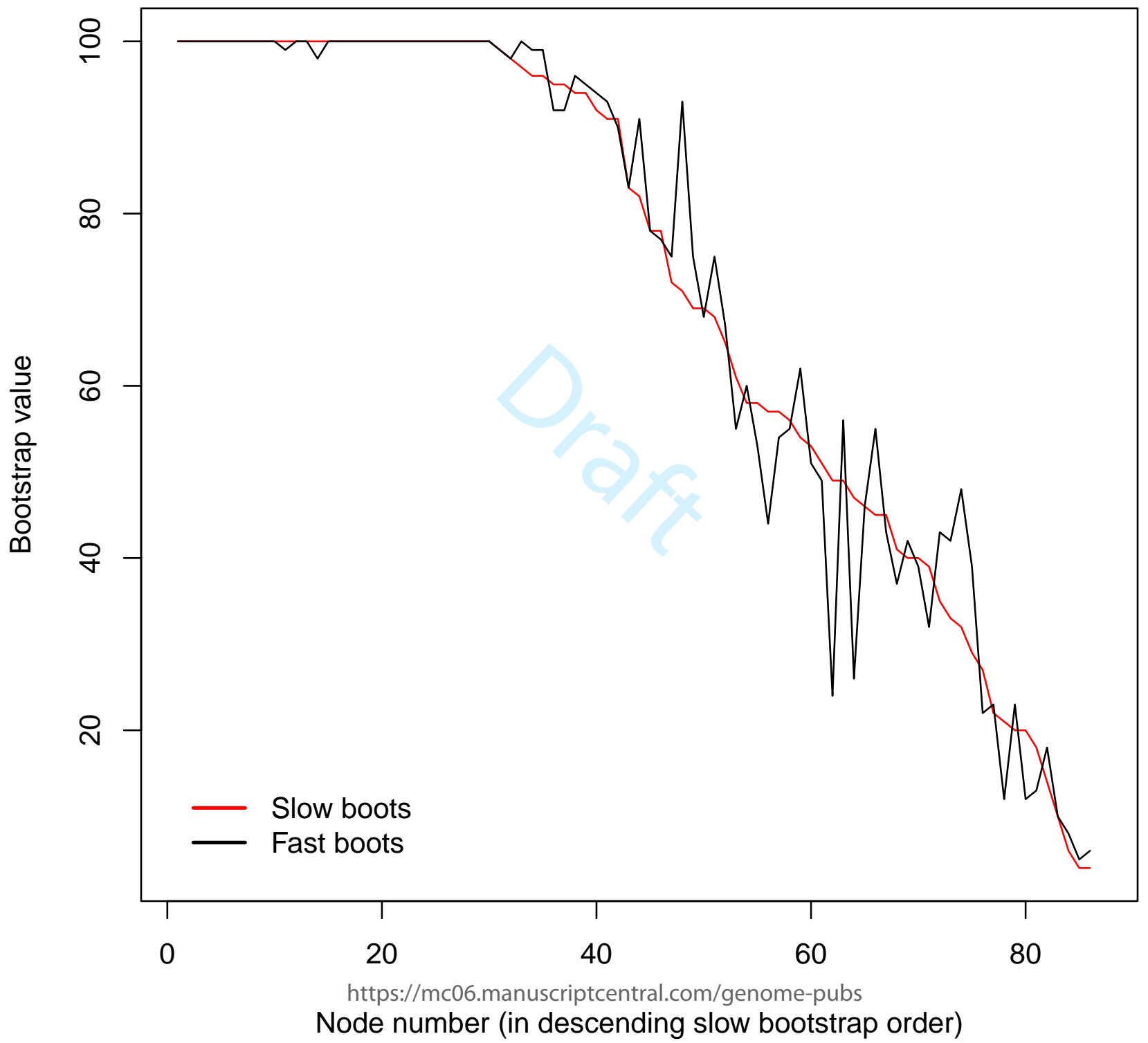


Supplement: Pham et al., Phylogenetic history and geography as joint predictors of oak chloroplast phylogeny

Chloroplast genome sequence information: samples, libraries, and assembly summaries

\begin{tabular}{|c|c|c|c|c|c|}
\hline RAxML tree label & organism & sample_title & bioproject_id & SRA_accn & loc \\
\hline alba_I_MOR359_I_USA-MN & Quercus alba L. & Quercus alba L. shotgun genomic sequencing, MOR_MH109|QUAL_MN_1 & PRJNA269970 & SAMN03264816 & USA-MN \\
\hline alba_I_USFSNC2_I_USA-NC & Quercus alba L. & Quercus alba L. shotgun genomic sequencing, USFS_NC2|QUAL_NC_2 & PRJNA269970 & SAMN03264817 & USA-NC \\
\hline alba_I_USFSPN1_I_USA-PN & Quercus alba L. & Quercus alba L. shotgun genomic sequencing, USFS_PN1|QUAL_PN_1 & PRJNA269970 & SAMN03264818 & USA-PN \\
\hline alba_I_USFSPN4_I_USA-PN & Quercus alba L. & Quercus alba L. shotgun genomic sequencing, USFS_PN4 |QUAL_PN_4 & PRJNA269970 & SAMN03264819 & USA-PN \\
\hline arizonica_I_MOR413_I_USA-AZ & Quercus arizonica Sarg. & Quercus arizonica Sarg. shotgun genomic sequencing, PM66|AZ-HU-15 & PRJNA269970 & SAMN03264796 & USA-AZ \\
\hline berberidifolia_I_MOR508_I_USA-CA & Quercus berberidifolia Liebm. & Quercus berberidifolia Liebm. shotgun genomic sequencing, MH47|CA-DAV-MH047 & PRJNA269970 & SAMN03264799 & USA-CA \\
\hline bicolor_I_MOR289_I_USA-KS & Quercus bicolor Willd. & Quercus bicolor Willd. shotgun genomic sequencing, IL_SH184|QUBI_KS_1 & PRJNA269970 & SAMN03264821 & USA-IL \\
\hline bicolor_I_MOR342_I_USA-IL & Quercus bicolor Willd. & Quercus bicolor Willd. shotgun genomic sequencing, MH94|QUBI_IL_1 & PRJNA269970 & SAMN03264820 & USA-IL \\
\hline boyntonii_I_MOR436_I_USA-AL & Quercus boyntonii Beadle & Quercus boyntonii Beadle shotgun genomic sequencing, IL-SH24|IL-SH-24 & PRJNA269970 & SAMN03264814 & USA-AL \\
\hline chrysolepis_I_MOR415_I_USA-AZ & Quercus chrysolepis Liebm. & Quercus chrysolepis Liebm. shotgun genomic sequencing|AZ-HU-17 & PRJNA269970 & SAMN03264797 & USA-AZ \\
\hline chrysolepis_I_MOR474_I_USA-CA & Quercus chrysolepis Liebm. & Quercus chrysolepis Liebm. shotgun genomic sequencing|CA-MH70 & PRJNA269970 & SAMN03264807 & USA-CA \\
\hline dentata_I_QD01_I_RUS & Quercus dentata Thunb. & Quercus dentata shotgun genomic sequence $\mid$ Qd_01 & PRJNA269970 & SAMN03653768 & RUS \\
\hline dentata_I_QD03_I_RUS & Quercus dentata Thunb. & Quercus dentata shotgun genomic sequence $\mid$ Qd_03 & PRJNA269970 & SAMN03653764 & RUS \\
\hline dentata_I_QD04_I_RUS & Quercus dentata Thunb. & Quercus dentata shotgun genomic sequence|Qd_04 & PRJNA269970 & SAMN03653765 & RUS \\
\hline dentata_I_QD05_I_RUS & Quercus dentata Thunb. & Quercus dentata shotgun genomic sequence $\mid \mathrm{Qd} \_05$ & PRJNA269970 & SAMN03653766 & RUS \\
\hline dentata_I_QD06_I_RUS & Quercus dentata Thunb. & Quercus dentata shotgun genomic sequence $\mid$ Qd_06 & PRJNA269970 & SAMN03653769 & RUS \\
\hline dentata_I_QD09_I_RUS & Quercus dentata Thunb. & Quercus dentata shotgun genomic sequence $\mid$ Qd_09 & PRJNA269970 & SAMN03653767 & RUS \\
\hline dentata_I_QD10_I_RUS & Quercus dentata Thunb. & Quercus dentata shotgun genomic sequence $\mid \mathrm{Qd} \_10$ & PRJNA269970 & SAMN03653762 & RUS \\
\hline douglasii_I_MOR531_I_USA-CA & Quercus douglasii Hook. \& Arn. & Quercus douglasii Hook. \& Arn. shotgun genomic sequencing, MH73|CA-MH-073 & PRJNA269970 & SAMN03264808 & USA-CA \\
\hline engelmannii_I_MOR406_I_USA-CA & Quercus engelmannii Greene & Quercus engelmannii Greene shotgun genomic sequencing, MH35|CA-DAV-MH035 & PRJNA269970 & SAMN03264801 & USA-CA \\
\hline gambelii_I_MOR387_I_USA-CO & Quercus gambelii Nutt. & Quercus gambelii Nutt. shotgun genomic sequencing, MH92 |IL-MOR-MHO92 & PRJNA269970 & SAMN03264809 & USA-CO \\
\hline gambelii_I_MOR546_I_USA-AZ & Quercus gambelii Nutt. & Quercus gambelii Nutt. shotgun genomic sequencing, PM62 |AZ-CH-11 & PRJNA269970 & SAMN03264795 & USA-AZ \\
\hline garryana_I_MOR422_I_USA-CA & Quercus garryana Douglas ex. Hc & c Quercus garryana Douglas ex. Hook. shotgun genomic sequencing, MH21|QUGA4_CA_1 & PRJNA269970 & SAMN03264823 & USA-CA \\
\hline garryana_I_USFSOR1_I_USA-OR & Quercus garryana Douglas ex. Hc & c Quercus garryana Douglas ex. Hook. shotgun genomic sequencing, USFS_OR1|QUGA4_OR_1 & 1 PRJNA269970 & SAMN03264824 & USA-OR \\
\hline lobata_I_MOR123_I_USA-CA & Quercus lobata Nee & Quercus lobata Nee shotgun genomic sequencing, MH53|CA-DAV-MH53 & PRJNA269970 & SAMN03264805 & USA-CA \\
\hline Iyrata_I_MOR385_I_USA-MO & Quercus lyrata Walter & Quercus lyrata Walter shotgun genomic sequencing, MH96|QULY_MO_1 & PRJNA269970 & SAMN03264826 & USA-MO \\
\hline Iyrata_I_MOR611_I_USA-GA & Quercus lyrata Walter & Quercus lyrata Walter shotgun genomic sequencing, MH78|QULY_GA_1 & PRJNA269970 & SAMN03264825 & USA-GA \\
\hline macrocarpa_I_MOR616_I_USA-NC & Quercus macrocarpa Michx. & Quercus macrocarpa Michx. shotgun genomic sequencing|IL-SH-187 & PRJNA269970 & SAMN03264813 & USA-NC \\
\hline macrocarpa_I_MOR672_I_USA-NM & Quercus macrocarpa Michx. & Quercus macrocarpa Michx. shotgun genomic sequencing|IL-SH-186 & PRJNA269970 & SAMN03264812 & USA-NM \\
\hline macrocarpa_I_MOR673_I_CAN-QU & Quercus macrocarpa Michx. & Quercus macrocarpa Michx. shotgun genomic sequencing, IL_SH190|QUMA2_QU_1 & PRJNA269970 & SAMN03264829 & CAN-QU \\
\hline macrocarpa_I_USFSKS1_I_USA-KS & Quercus macrocarpa Michx. & Quercus macrocarpa Michx. shotgun genomic sequencing|QUMA2_KS_1 & PRJNA269970 & SAMN03264827 & USA-KS \\
\hline macrocarpa_I_USFSWI3_I_USA-WI & Quercus macrocarpa Michx. & Quercus macrocarpa Michx. shotgun genomic sequencing|QUMA2_WI_3 & PRJNA269970 & SAMN03264830 & USA-WI \\
\hline margarettae_I_MOR420_I_USA-TX & Quercus margaretta (Ashe) Small & | Quercus margarettae (Ashe) Small shotgun genomic sequencing|CA-DAV-MH50 & PRJNA269970 & SAMN03264804 & USA-TX \\
\hline
\end{tabular}


michauxii_I_MOR353_I_USA-MO michauxii_I_MOR694_I_USA-IN michauxii_I_MOR700_I_USA-IL mohriana_I_MOR125_I_USA-TX mongolica_I_MOR360_I_CHI-Be mongolica_I_OPB13_I_RUS mongolica_I_OPB21_I_RUS mongolica_I_OPB26_I_RUS mongolica_I_OPL19_I_RUS mongolica_I_OPL20_I_RUS mongolica_I_OPL21_I_RUS mongolica_I_OTO14_I_RUS mongolica_I_OTO3_I_RUS mongolica_I_OVLO2_I_RUS mongolica_I_OVLO4_I_RUS mongolica_I_OVL14_I_RUS mongolica_I_QKOR2_I_SKO mongolica_I_QKOR7_I_SKO mongolica_I_QKOR8_I_SKO mongolica_I_QM14_I_RUS mongolica_I_QM18_I_RUS mongolica_I_QM20_I_RUS mongolica_I_QM42_I_CHI mongolica_I_QM44_I_CHI mongolica_I_QM49_I_CHI mongolica_I_QM65_I_RUS mongolica_I_QM68_I_RUS mongolica_I_QM71_I_RUS mongolica_I_QMSUW4_I_SKO muehlenbergii_I_MOR383_I_USA-IL muehlenbergii_I_MOR632_I_USA-OK muehlenbergii_I_MOR639_I_USA-TX petraea_I_HB175_I_GER petraea_I_HB181_I_GER petraea_I_MOR520_I_POL petraea_I_MST29_I_GER petraea_I_MST30_I_GER petraea_I_MST31_I_GER prinoides_I_MOR352_I_USA-VA
Quercus michauxii Nutt.

Quercus michauxii Nutt. shotgun genomic sequencing, MH1|QUMI_MO_1

Quercus michauxii Nutt. shotgun genomic sequencing, MH79|QUMI_IN_1

Quercus michauxii Nutt. shotgun genomic sequencing, IL_SH154|QUMI_IL_1

Quercus mohriana Buckley ex Ryc Quercus mohriana Buckley ex Rydb. shotgun genomic sequencing, MH51|CA-DAV-MH051 PRJNA269970

Quercus mongolica Fisch. Ex Led€ Quercus mongolica Fisch. Ex Ledeb. shotgun genomic sequencing, MH106|QUMO5_CH_1 PRJNA269970

Quercus mongolica Fisch. Ex Led€ Quercus mongolica shotgun genomic sequence |Opb_13

Quercus mongolica Fisch. Ex Led€ Quercus mongolica shotgun genomic sequence $\mid \mathrm{Opb} \_21$

Quercus mongolica Fisch. Ex Led€ Quercus mongolica shotgun genomic sequence | Opb_26 Quercus mongolica Fisch. Ex Led€ Quercus mongolica shotgun genomic sequence|Opl_19

Quercus mongolica Fisch. Ex Led€ Quercus mongolica shotgun genomic sequence |Opl_20 Quercus mongolica Fisch. Ex Led€ Quercus mongolica shotgun genomic sequence |Opl_21 Quercus mongolica Fisch. Ex Led€ Quercus mongolica shotgun genomic sequence |Oto_14 Quercus mongolica Fisch. Ex Led€ Quercus mongolica shotgun genomic sequence |0to_03 Quercus mongolica Fisch. Ex Led€ Quercus mongolica shotgun genomic sequence | OvI_02 Quercus mongolica Fisch. Ex Led€ Quercus mongolica shotgun genomic sequence|OvI_04 Quercus mongolica Fisch. Ex Led€ Quercus mongolica shotgun genomic sequence |Ovl_14 Quercus mongolica Fisch. Ex Led€ Quercus mongolica shotgun genomic sequence|Qkor_02 Quercus mongolica Fisch. Ex Led€ Quercus mongolica shotgun genomic sequence |Qkor_07 Quercus mongolica Fisch. Ex Led€ Quercus mongolica shotgun genomic sequence|Qkor_08 Quercus mongolica Fisch. Ex Led€ Quercus mongolica shotgun genomic sequence |Qm_14 Quercus mongolica Fisch. Ex Led€ Quercus mongolica shotgun genomic sequence|Qm_18 Quercus mongolica Fisch. Ex Led€ Quercus mongolica shotgun genomic sequence |Qm_20 Quercus mongolica Fisch. Ex Led€ Quercus mongolica shotgun genomic sequence $\mid \mathrm{Qm} \_42$ Quercus mongolica Fisch. Ex Led€ Quercus mongolica shotgun genomic sequence |Qm_44 Quercus mongolica Fisch. Ex Led $€$ Quercus mongolica shotgun genomic sequence $\mid$ Om_ 49 Quercus mongolica Fisch. Ex Led€ Quercus mongolica shotgun genomic sequence |Qm_65 Quercus mongolica Fisch. Ex Led $€$ Quercus mongolica shotgun genomic sequence $\mid \mathrm{Qm} \_68$ Quercus mongolica Fisch. Ex Led€ Quercus mongolica shotgun genomic sequence $\mid$ Qm__71 Quercus mongolica Fisch. Ex Led€ Quercus mongolica shotgun genomic sequence|Qm_SUW_4

Quercus muehlenbergii Engelm. Quercus muehlenbergii Engelm. shotgun genomic sequencing, MH103|IL-MOR-MH103 Quercus muehlenbergii Engelm. Quercus muehlenbergii Engelm. shotgun genomic sequencing, IL_SH57||L-SH-57 Quercus muehlenbergii Engelm. Quercus muehlenbergii Engelm. shotgun genomic sequencing, MH49|CA-DAV-MH49 Quercus petraea (Mattuschka) Lif Quercus petraea shotgun genomic sequence|HB_175 Quercus petraea (Mattuschka) Lii Quercus petraea shotgun genomic sequence|HB_181 Quercus petraea (Mattuschka) Lif Quercus petraea (Mattuschka) Liebl. shotgun genomic sequencing, MH97|QUPE2_PO_1 Quercus petraea (Mattuschka) Lif Quercus petraea shotgun genomic sequence|MST_29 Quercus petraea (Mattuschka) Lif Quercus petraea shotgun genomic sequence|MST_30 Quercus petraea (Mattuschka) Lif Quercus petraea shotgun genomic sequence|MST_31 Quercus prinoides Willd. Quercus prinoides Willd. shotgun genomic sequencing, MH7|QUPR2_VA_1
PRJNA269970

PRJNA269970

PRJNA269970

PRJNA269970

PRJNA269970

PRJNA269970

PRJNA269970

PRJNA269970

PRJNA269970

PRJNA269970

PRJNA269970

PRINA269970

PRJNA269970

PRJNA269970

PRJNA269970

PRJNA269970

PRJNA269970

PRJNA269970

PRJNA269970

PRJNA269970

PRJNA269970

PRJNA269970

PRINA269970

PRJNA269970

PRJNA269970

PRJNA269970

PRJNA269970

PRJNA269970

PRJNA269970

PRJNA269970

PRJNA269970

PRJNA269970

PRJNA269970

PRJNA269970

PRJNA269970
SAMN03264833

SAMN03264832

SAMN0326483

SAMN03264800

SAMN03264834

SAMN03653770

AMN0365377

SAMN03653772

SAMN03653773

SAMN03653774

SAMN03653775

SAMN03653776

SAMN03653777

SAMN03653779

SAMN03653780

SAMN03653778

SAMN03653781

SAMN03653782

SAMN03653803

SAMN03653784

SAMN03653785

SAMN03653786

SAMN03653800

SAMN03653801

SAMN03653802

SAMN03653787

SAMN03653788

SAMN03653789

SAMN03653783

SAMN03264810

SAMN03264815

SAMN03264803

SAMN03653790

SAMN03653791

SAMN03264835

SAMN03653792

SAMN03653793

SAMN03653794

SAMN03264838
USA-MO USA-IN

USA-IL USA-TX $\mathrm{CHI}-\mathrm{Be}$ RUS RUS 
prinoides_I_MOR532_I_USA-NE prinoides_I_USFSNC1_I_USA-NC prinoides_I_USFSPN1_I_USA-PN robur_I_ARK15_I_RUS

robur_I_B2_1_I_RUS robur_I_MOR392_I_RUS

robur_I_PIEO6_I_FRA

robur_I_PIE10_I_FRA

robur_I_SVTO6_I_UKR

robur_I_SVT11_I_UKR

robur_I_TAM01_I_FIN

robur_I_TAM10_I_FIN

robur_I_WR4_1_I_BEL

robur_I_WR4_7_I_BEL

stellata_I_MOR388_I_USA-IA

stellata_I_USFSGA2_I_USA-WI

tomentella_I_MOR133_I_USA-CA

vacciniifolia_I_MOR377__ USA-CA

vaseyana_I_MOR397_I_USA-TX
Quercus prinoides Willd

Quercus prinoides Willd.

Quercus prinoides Willd.

Quercus robur L.

Quercus robur L.

Quercus robur $\mathrm{L}$.

Quercus robur L.

Quercus robur L.

Quercus robur $L$.

Quercus robur L.

Quercus robur L.

Quercus robur L.

Quercus robur L.

Quercus stellata Wangenh.

Quercus stellata Wangenh.

Quercus tomentella Engelm.

Quercus vacciniifolia Kellogg

Quercus vaseyana Buckley
Quercus prinoides Willd. shotgun genomic sequencing, IL_SH96|IL-SH-096

Quercus prinoides Willd. shotgun genomic sequencing|QUPR2_NC_1

Quercus prinoides Willd. shotgun genomic sequencing|QUPR2_PN_1

Quercus robur shotgun genomic sequence|ARK_15

Quercus robur shotgun genomic sequence $\mid \mathrm{B} 2$

Quercus robur L. shotgun genomic sequencing, MH84|QURO2_RU_1

Quercus robur shotgun genomic sequence |PIE_ 06

Quercus robur shotgun genomic sequence|PIE_10

Quercus robur shotgun genomic sequence|SVT_06

Quercus robur shotgun genomic sequence|SVT_11

Quercus robur shotgun genomic sequence |TAM_01

Quercus robur shotgun genomic sequence |TAM_10

Quercus robur shotgun genomic sequence |WR4_01

Quercus robur shotgun genomic sequence|WR4_07

Quercus stellata Wangenh. shotgun genomic sequencing, MH95|QUST_IA_1

Quercus stellata Wangenh. shotgun genomic sequencing|QUST_GA_2

Quercus tomentella Engelm. shotgun genomic sequencing, MH14|CA-DAV-MH14

Quercus vacciniifolia Kellogg shotgun genomic sequencing, MH68|CA-MH068

Quercus vaseyana Buckley shotgun genomic sequencing, MH39|CA-DAV-MH039
PRINA269970

PRJNA269970

PRINA269970

PRJNA269970

PRINA269970

PRJNA269970

PRJNA269970

PRJNA269970

PRJNA269970

PRJNA269970

PRJNA269970

PRJNA269970

PRJNA269970

PRJNA269970

PRJNA269970

PRJNA269970

PRJNA269970

PRJNA269970

PRJNA269970
SAMN03264811

SAMN03264836

SAMN03264837

SAMN03653809

SAMN03653795

SAMN03264839

SAMN03653797

SAMN03653796

SAMN03653807

SAMN03653808

SAMN03653798

SAMN03653799

SAMN03653805

SAMN03653806

SAMN03264841

SAMN03264840

SAMN03264802

SAMN03264806

SAMN03264798
SA-NE

SA-NC

USA-PN

FRA 


\begin{tabular}{|c|c|c|c|c|c|c|c|}
\hline Floragenex & collected_by & collection_date & geo_loc_name & lat_lon & specimen_vouche & biomaterial_provider & platform \\
\hline \multirow[t]{4}{*}{ MOR359 } & D. Keiser & & USA: Minnesota & $45.3 \mathrm{~N} 93.2 \mathrm{~W}$ & MOR 174462 & Morton Arboretum, Lisle, IL & HiSeq_2000_100PE \\
\hline & P. Berrang & $10 / 1 / 2013$ & USA: North Carolina & 35.25357 N $82.19709 \mathrm{~W}$ & & USDA Forest Service, Milwaukee, W & HiSeq_2000_100PE \\
\hline & S. Forry & 9/20/2013 & USA: Pennsylvania & $41.38389 \mathrm{~N} 79.0540 \mathrm{~W}$ & & USDA Forest Service, Alegheny Nati & HiSeq_2000_100PE \\
\hline & S. Forry & 9/20/2013 & USA: Pennsylvania & 41.50643 N 79.24511 & & USDA Forest Service, Alegheny Natii & HiSeq_2000_100PE \\
\hline MOR413 & \multicolumn{2}{|c|}{ Andrew Hipp, Paul Manos, Jeanninє 6/4/2012 } & USA: Arizona & $31.4495 \mathrm{~N}, 109.2431 \mathrm{~W}$ & MOR 174229 & Morton Arboretum, Lisle, IL & HiSeq_2000_100PE \\
\hline MOR508 & R. Gankin \& J.B. Jaacov & $5 / 11 / 2012$ & USA: California & $38.4 \mathrm{~N}, 122.0 \mathrm{~W}$ & MOR 174692 & Morton Arboretum, Lisle, IL & HiSeq_2000_100PE \\
\hline MOR289 & A. Hipp & & USA: Kansas & $38.9048 \mathrm{~N} 94.8926 \mathrm{~W}$ & & Morton Arboretum, Lisle, IL & HiSeq_2000_100PE \\
\hline MOR342 & M. Hahn, B.G. Budaitis, , E.M. Meza & 5/24/2012 & USA: Illinois & 41.7357 N $87.8565 \mathrm{~W}$ & MOR174534 & Morton Arboretum, Lisle, IL & HiSeq_2000_100PE \\
\hline MOR436 & R. Lance \& A. Hipp & 1999 & USA: Alabama & $34.0 \mathrm{~N} 86.0 \mathrm{~W}$ & MOR 175278 & Morton Arboretum, Lisle, IL & HiSeq_2000_100PE \\
\hline MOR415 & Andrew Hipp, Paul Manos, Jeannin€ & 6/4/2012 & USA: Arizona & $31.4334 \mathrm{~N}, 109.2431 \mathrm{~W}$ & MOR 174230 & Morton Arboretum, Lisle, IL & HiSeq_2000_100PE \\
\hline \multirow[t]{8}{*}{ MOR474 } & unknown & & USA: California & unknown & MOR 174682 & Morton Arboretum, Lisle, IL & HiSeq_2000_100PE \\
\hline & B. Degen & 2012 & Russia & $42.801233 \mathrm{~N} 131.245433 \mathrm{E}$ & & Thuenen Institute of Forest Genetic & HiSeq_2000_100PE \\
\hline & B. Degen & 2012 & Russia & $42.801267 \mathrm{~N} 131.245467 \mathrm{E}$ & & Thuenen Institute of Forest Genetic & HiSeq_2000_100PE \\
\hline & B. Degen & 2012 & Russia & $42.801283 \mathrm{~N} 131.245483 \mathrm{E}$ & & Thuenen Institute of Forest Genetic & HiSeq_2000_100PE \\
\hline & B. Degen & 2012 & Russia & $42.8013 \mathrm{~N} 131.2455 \mathrm{E}$ & & Thuenen Institute of Forest Genetic & HiSeq_2000_100PE \\
\hline & B. Degen & 2012 & Russia & 42.801317 N $131.245517 \mathrm{E}$ & & Thuenen Institute of Forest Genetic & HiSeq_2000_100PE \\
\hline & B. Degen & 2012 & Russia & $42.801367 \mathrm{~N} 131.245567 \mathrm{E}$ & & Thuenen Institute of Forest Genetic & HiSeq_2000_100PE \\
\hline & B. Degen & 2012 & Russia & $42.801383 \mathrm{~N} 131.245583 \mathrm{E}$ & & Thuenen Institute of Forest Genetic & HiSeq_2000_100PE \\
\hline MOR531 & unknown & & USA: California & unknown & MOR 174681 & Morton Arboretum, Lisle, IL & HiSeq_2000_100PE \\
\hline MOR406 & W. Roderick & & USA: California & $32.6 \mathrm{~N}, 116.9 \mathrm{~W}$ & MOR 174583 & Morton Arboretum, Lisle, IL & HiSeq_2000_100PE \\
\hline MOR387 & unknown & & USA: Colorado & $38.8 \mathrm{~N} 105.2 \mathrm{~W}$ & MOR 174463 & Morton Arboretum, Lisle, IL & HiSeq_2000_100PE \\
\hline MOR546 & Andrew Hipp, Paul Manos, Jeanninє & 6/2/2012 & USA: Arizona & $31.7566 \mathrm{~N}, 109.2431 \mathrm{~W}$ & MOR 174218 & Morton Arboretum, Lisle, IL & HiSeq_2000_100PE \\
\hline \multirow[t]{2}{*}{ MOR422 } & R. Gankin \& G.L. Stebbins & & USA: California & $38.6946 \mathrm{~N} 120.8149 \mathrm{~W}$ & MOR174699 & Morton Arboretum, Lisle, IL & HiSeq_2000_100PE \\
\hline & T. Jennings & & USA: Oregon & $43.3050 \mathrm{~N} 123.2412 \mathrm{~W}$ & & USDA Forest Service, Corvallis, OR & HiSeq_2000_100PE \\
\hline MOR123 & L. Waters & & USA: California & $36.5 \mathrm{~N} 120.9 \mathrm{~W}$ & MOR 174703 & Morton Arboretum, Lisle, IL & HiSeq_2000_100PE \\
\hline MOR385 & A. Hipp & & USA: Missouri & $36.7209 \mathrm{~N} 90.1129 \mathrm{~W}$ & & Morton Arboretum, Lisle, IL & HiSeq_2000_100PE \\
\hline MOR611 & R. Lance & & USA: Georgia & 30.7084 N $84.8564 \mathrm{~W}$ & & Morton Arboretum, Lisle, IL & HiSeq_2000_100PE \\
\hline MOR616 & unknown & & USA: North Carolina & $35.4 \mathrm{~N} 82.4 \mathrm{~W}$ & MOR 175244 & Morton Arboretum, Lisle, IL & HiSeq_2000_100PE \\
\hline MOR672 & unknown & & USA: New Mexico & $33.6 \mathrm{~N} 105.4 \mathrm{~W}$ & MOR 175314 & Morton Arboretum, Lisle, IL & HiSeq_2000_100PE \\
\hline \multirow[t]{3}{*}{ MOR673 } & & & Canada: Quebec & $45.5129 \mathrm{~N} 73.5506 \mathrm{~W}$ & & Morton Arboretum, Lisle, IL & HiSeq_2000_100PE \\
\hline & R. Cronn & & USA: Kansas & $39.0286 \mathrm{~N} 94.9404 \mathrm{~W}$ & & USDA Forest Service, Corvallis, OR & HiSeq_2000_100PE \\
\hline & P. Berrang & & USA: Wisconsin & $42.8751 \mathrm{~N} 88.3276 \mathrm{~W}$ & & USDA Forest Service, Milwaukee, W & HiSeq_2000_100PE \\
\hline MOR420 & D. Cavagnaro & 10/27/1963 & USA: Texas & $29.6 \mathrm{~N} 97.6 \mathrm{~W}$ & MOR 174705 & Morton Arboretum, Lisle, IL & HiSeq_2000_100PE \\
\hline
\end{tabular}




\begin{tabular}{|c|c|c|c|c|c|c|c|}
\hline MOR353 & P. J. van der Linden & & USA: Missouri & 36.6447 N $89.2850 \mathrm{~W}$ & & Morton Arboretum, Lisle, IL & HiSeq_2000_100PE \\
\hline MOR694 & Friesner & & USA: Indiana & & & Morton Arboretum, Lisle, IL & HiSeq_2000_100PE \\
\hline MOR700 & A. Hipp & & USA: Illinois & $37.1393 \mathrm{~N} 89.3429 \mathrm{~W}$ & & Morton Arboretum, Lisle, IL & HiSeq_2000_100PE \\
\hline MOR125 & D. Cavagnaro & 10/11/1963 & USA: Texas & $32.0 \mathrm{~N}, 104.7 \mathrm{~W}$ & MOR 174704 & Morton Arboretum, Lisle, IL & HiSeq_2000_100PE \\
\hline \multirow[t]{25}{*}{ MOR360 } & & & China & $40.5 \mathrm{~N} 116.7 \mathrm{E}$ & & Morton Arboretum, Lisle, IL & HiSeq_2000_100PE \\
\hline & B. Degen & 2012 & Russia & $50.187167 \mathrm{~N} 138.591 \mathrm{E}$ & & Thuenen Institute of Forest Genetic & HiSeq_2000_100PE \\
\hline & B. Degen & 2012 & Russia & $50.187167 \mathrm{~N} 138.591 \mathrm{E}$ & & Thuenen Institute of Forest Genetic & HiSeq_2000_100PE \\
\hline & B. Degen & 2012 & Russia & $50.187167 \mathrm{~N} 138.591 \mathrm{E}$ & & Thuenen Institute of Forest Genetic & HiSeq_2000_100PE \\
\hline & B. Degen & 2012 & Russia & $43.374833 \mathrm{~N} 133.892 \mathrm{E}$ & & Thuenen Institute of Forest Genetic & HiSeq_2000_100PE \\
\hline & B. Degen & 2012 & Russia & $43.374833 \mathrm{~N} 133.892 \mathrm{E}$ & & Thuenen Institute of Forest Genetic & HiSeq_2000_100PE \\
\hline & B. Degen & 2012 & Russia & $43.374833 \mathrm{~N} 133.892 \mathrm{E}$ & & Thuenen Institute of Forest Genetic & HiSeq_2000_100PE \\
\hline & B. Degen & 2012 & Russia & $49.0497 \mathrm{~N} 131.860333 \mathrm{E}$ & & Thuenen Institute of Forest Genetic & HiSeq_2000_100PE \\
\hline & B. Degen & 2012 & Russia & $49.0497 \mathrm{~N} 131.860333 \mathrm{E}$ & & Thuenen Institute of Forest Genetic & HiSeq_2000_100PE \\
\hline & B. Degen & 2012 & Russia & $43.073167 \mathrm{~N} 131.909833 \mathrm{E}$ & & Thuenen Institute of Forest Genetic & HiSeq_2000_100PE \\
\hline & B. Degen & 2012 & Russia & $43.073167 \mathrm{~N} 131.909833 \mathrm{E}$ & & Thuenen Institute of Forest Genetic & HiSeq_2000_100PE \\
\hline & B. Degen & 2012 & Russia & 43.073167 N $131.909833 \mathrm{E}$ & & Thuenen Institute of Forest Genetic & HiSeq_2000_100PE \\
\hline & B. Degen & August 2012 & South Korea & $37.5667 \mathrm{~N} 126.9781 \mathrm{E}$ & & Thuenen Institute of Forest Genetic & HiSeq_2000_100PE \\
\hline & B. Degen & August 2012 & South Korea & $37.5667 \mathrm{~N} 126.9781 \mathrm{E}$ & & Thuenen Institute of Forest Genetic & HiSeq_2000_100PE \\
\hline & B. Degen & August 2012 & South Korea & & & Thuenen Institute of Forest Genetic & HiSeq_2000_100PE \\
\hline & B. Degen & \multicolumn{2}{|c|}{ 16. September 20 Russia } & $45.083333 \mathrm{~N} 133.947194 \mathrm{E}$ & & Thuenen Institute of Forest Genetic & HiSeq_2000_100PE \\
\hline & B. Degen & \multicolumn{2}{|c|}{ 16. September 20 Russia } & 46.083028 N $133.945889 \mathrm{E}$ & & Thuenen Institute of Forest Genetic & HiSeq_2000_100PE \\
\hline & B. Degen & \multicolumn{2}{|c|}{ 16. September 20 Russia } & $46.082194 \mathrm{~N} 133.945556 \mathrm{E}$ & & Thuenen Institute of Forest Genetic & HiSeq_2000_100PE \\
\hline & B. Degen & \multicolumn{2}{|c|}{ 19. September 20 China } & 45.429692 N $127.092031 \mathrm{E}$ & & Thuenen Institute of Forest Genetic & HiSeq_2000_100PE \\
\hline & B. Degen & \multicolumn{2}{|c|}{ 19. September 20 China } & $45.429531 \mathrm{~N} 127.091156 \mathrm{E}$ & & Thuenen Institute of Forest Genetic & HiSeq_2000_100PE \\
\hline & B. Degen & \multicolumn{2}{|c|}{ 19. September 20 China } & $45.428283 \mathrm{~N} 127.090569 \mathrm{E}$ & & Thuenen Institute of Forest Genetic & HiSeq_2000_100PE \\
\hline & B. Degen & 2012 & Russia & 48.619717 N $135.90783 \mathrm{E}$ & & Thuenen Institute of Forest Genetic & HiSeq_2000_100PE \\
\hline & B. Degen & 2012 & Russia & $48.619717 \mathrm{~N} 135.90783 \mathrm{E}$ & & Thuenen Institute of Forest Genetic & HiSeq_2000_100PE \\
\hline & B. Degen & 2012 & Russia & $48.619717 \mathrm{~N} 135.90783 \mathrm{E}$ & & Thuenen Institute of Forest Genetic & HiSeq_2000_100PE \\
\hline & B. Degen & July 2014 & South Korea & $37.5667 \mathrm{~N} 126.9781 \mathrm{E}$ & & Thuenen Institute of Forest Genetic & HiSeq_2000_100PE \\
\hline MOR383 & C. Shaw & & USA: Illinois & $41.2 \mathrm{~N} 88.0 \mathrm{~W}$ & MOR 174533 & Morton Arboretum, Lisle, IL & HiSeq_2000_100PE \\
\hline MOR632 & unknown & & USA: Oklahoma & $35.7 \mathrm{~N} 98.9 \mathrm{~W}$ & MOR 175345 & Morton Arboretum, Lisle, IL & HiSeq_2000_100PE \\
\hline \multirow[t]{3}{*}{ MOR639 } & unknown & & USA: Texas & $32.00 \mathrm{~N} 104.8 \mathrm{~W}$ & MOR 174690 & Morton Arboretum, Lisle, IL & HiSeq_2000_100PE \\
\hline & B. Degen & & Germany & $53.700539 \mathrm{~N} 10.719256 \mathrm{E}$ & & Thuenen Institute of Forest Genetic & HiSeq_2000_100PE \\
\hline & B. Degen & & Germany & $53.700539 \mathrm{~N} 10.719256 \mathrm{E}$ & & Thuenen Institute of Forest Genetic & HiSeq_2000_100PE \\
\hline \multirow[t]{4}{*}{ MOR520 } & & & Poland & $51.8 \mathrm{~N} 19.8 \mathrm{E}$ & & Morton Arboretum, Lisle, IL & HiSeq_2000_100PE \\
\hline & B. Degen & 18. May 2005 & Germany & 51.909356 N $7.740925 \mathrm{E}$ & & Thuenen Institute of Forest Genetic & HiSeq_2000_100PE \\
\hline & B. Degen & 18. May 2005 & Germany & 51.909356 N $7.740925 \mathrm{E}$ & & Thuenen Institute of Forest Genetic & HiSeq_2000_100PE \\
\hline & B. Degen & 18. May 2005 & Germany & 51.909356 N $7.740925 \mathrm{E}$ & & Thuenen Institute of Forest Genetic & HiSeq_2000_100PE \\
\hline MOR352 & A. Hipp & & USA: Virginia & 37.1414 N 79.9957 W & & Morton Arboretum, Lisle, IL & HiSeq_2000_100PE \\
\hline
\end{tabular}




\begin{tabular}{|c|c|c|c|c|}
\hline \multirow[t]{5}{*}{ MOR532 } & G. Morgenson & & USA: Nebraska & $40.0 \mathrm{~N} 95.7 \mathrm{~W}$ \\
\hline & P. Berrang & & USA: North Carolina & 35.2535 N 82.1970 W \\
\hline & S. Forry & & USA: Pennsylvania & $41.5073 \mathrm{~N} 79.2442 \mathrm{~W}$ \\
\hline & B. Degen & 2013 & Russia & $54.416667 \mathrm{~N} 56.666667 \mathrm{E}$ \\
\hline & B. Degen & 2008 & Russia & 52.674197 N $58.742517 \mathrm{E}$ \\
\hline \multirow[t]{9}{*}{ MOR392 } & & & Russia & $55.8 \mathrm{~N} 37.6 \mathrm{E}$ \\
\hline & B. Degen & 20. July 2009 & France & $44.737028 \mathrm{~N}-0.776389 \mathrm{~W}$ \\
\hline & B. Degen & 20. July 2009 & France & $44.737028 \mathrm{~N}-0.776389 \mathrm{~W}$ \\
\hline & B. Degen & 2013 & Ukraine & 49.052833 N $37.9295 E$ \\
\hline & B. Degen & 2013 & Ukraine & 49.052833 N $37.9295 E$ \\
\hline & B. Degen & 03. June 2008 & Finland & $59.974439 \mathrm{~N} 23.435525 \mathrm{E}$ \\
\hline & B. Degen & 03. June 2008 & Finland & $59.974439 \mathrm{~N} 23.435525 \mathrm{E}$ \\
\hline & B. Degen & 2013 & Belarus & $53.685833 \mathrm{~N} 23.792833 \mathrm{E}$ \\
\hline & B. Degen & 2013 & Belarus & $53.685833 \mathrm{~N} 23.792833 \mathrm{E}$ \\
\hline \multirow[t]{2}{*}{ MOR388 } & P. J. van der Linden & & USA: Iowa & 40.6123 N 91.6857 W \\
\hline & P. Berrang & & USA: Wisconsin & 33.9025 N 83.3824 W \\
\hline MOR133 & R. Gankin & 9/8/1968 & USA: California & $34.0 \mathrm{~N}, 119.6 \mathrm{~W}$ \\
\hline MOR377 & unknown & & USA: California & $38.8 \mathrm{~N} 120.1 \mathrm{~W}$ \\
\hline MOR397 & D. Cavagnaro & $10 / 7 / 1963$ & USA: Texas & $30.0 \mathrm{~N}, 101.2 \mathrm{~W}$ \\
\hline
\end{tabular}

\begin{tabular}{|c|c|c|}
\hline MOR 175238 & Morton Arboretum, Lisle, IL & HiSeq_2000_100PE \\
\hline & USDA Forest Service, Milwaukee, W & HiSeq_2000_100PE \\
\hline & USDA Forest Service, Alegheny Nati & HiSeq_2000_100PE \\
\hline & Thuenen Institute of Forest Genetic & HiSeq_2000_100PE \\
\hline & Thuenen Institute of Forest Genetic & HiSeq_2000_100PE \\
\hline & Morton Arboretum, Lisle, IL & HiSeq_2000_100PE \\
\hline & Thuenen Institute of Forest Genetic & HiSeq_2000_100PE \\
\hline & Thuenen Institute of Forest Genetic & HiSeq_2000_100PE \\
\hline & Thuenen Institute of Forest Genetic & HiSeq_2000_100PE \\
\hline & Thuenen Institute of Forest Genetic & HiSeq_2000_100PE \\
\hline & Thuenen Institute of Forest Genetic & HiSeq_2000_100PE \\
\hline & Thuenen Institute of Forest Genetic & HiSeq_2000_100PE \\
\hline & Thuenen Institute of Forest Genetic & HiSeq_2000_100PE \\
\hline & Thuenen Institute of Forest Genetic & HiSeq_2000_100PE \\
\hline & Morton Arboretum, Lisle, IL & HiSeq_2000_100PE \\
\hline & USDA Forest Service, Milwaukee, $\mathrm{W}$ & HiSeq_2000_100PE \\
\hline MOR 174688 & Morton Arboretum, Lisle, IL & HiSeq_2000_100PE \\
\hline IOR 174684 & Morton Arboretum, Lisle, IL & HiSeq_2000_100PE \\
\hline IOR 174580 & Morton Arboretum, Lisle, IL & HiSeq_2000_100PE \\
\hline
\end{tabular}




\begin{tabular}{|c|c|c|c|c|c|c|c|c|c|c|}
\hline sample ID & index & yield (Mb) & $\begin{array}{c}\text { sequence } \\
\text { reads }\end{array}$ & $\begin{array}{l}\text { Mean Q Score } \\
\text { (PF) }\end{array}$ & $\begin{array}{c}\text { mapped } c p \\
\text { reads }\end{array}$ & $\%$ сp & $\begin{array}{c}\text { coverage } \\
\text { depth, mean }\end{array}$ & $\begin{array}{c}\text { assembly } \\
\text { ACGT_count }\end{array}$ & $\begin{array}{l}\text { assembly } \\
\text { N_count }\end{array}$ & $\begin{array}{c}\text { assembly } \\
\text { length }\end{array}$ \\
\hline lane1-index703-D508-CGCTCATT-GTACTGAC-QUAL_MN_1 & GTACTGAC & 595 & 6,373,964 & 34.87 & 249664 & $3.92 \%$ & 170.6 & 135303 & 77 & 135380 \\
\hline lane1-index704-D501-GAGATTCC-TATAGCCT-QUAL_NC_2 & $\begin{array}{l}\text { OAGAIILL- } \\
\text { TATAGSTT }\end{array}$ & 1,399 & $14,782,704$ & 35.47 & 369454 & $2.50 \%$ & 245.0 & 135312 & 78 & 135390 \\
\hline lane1-index704-D505-GAGATTCC-AGGCGAAG-QUAL_PN_1 & SAIILL- & 586 & $6,322,916$ & 33.56 & 124491 & $1.97 \%$ & 78.8 & 135291 & 100 & 135391 \\
\hline lane1-index704-D508-GAGATTCC-GTACTGAC-QUAL_VT_4 & GAGAITL & 501 & $5,488,628$ & 32.54 & 106476 & $1.94 \%$ & 69.7 & 135291 & 94 & 135385 \\
\hline lane1-index701-D502-ATTACTCG-ATAGAGGC-AZ-HU-15 & & 849 & $9,084,856$ & 35.02 & 404289 & $4.45 \%$ & 289.2 & 135315 & 78 & 135393 \\
\hline lane1-index701-D505-ATTACTCG-AGGCGAAG-CA-DAV-MH047 & & 933 & $10,140,768$ & 33.99 & 696427 & $6.87 \%$ & 500.9 & 135258 & 77 & 135335 \\
\hline lane1-index705-D503-ATTCAGAA-CCTATCCT-QUBI_KS_1 & & 639 & $6,817,672$ & 34.82 & 222426 & $3.26 \%$ & 150.3 & 135309 & 80 & 135389 \\
\hline lane1-index705-D502-ATTCAGAA-ATAGAGGC-QUBI_IL_1 & & 663 & $7,108,492$ & 34.33 & 304107 & $4.28 \%$ & 210.1 & 135325 & 73 & 135398 \\
\hline lane1-index703-D504-CGCTCATT-GGCTCTGA-IL-SH-24 & & 590 & $6,366,160$ & 34.41 & 197645 & $3.10 \%$ & 140.3 & 135293 & 94 & 135387 \\
\hline lane1-index701-D503-ATTACTCG-CCTATCCT-AZ-HU-17 & & 1,165 & $12,559,072$ & 34.85 & 633634 & $5.05 \%$ & 454.0 & 135073 & 110 & 135183 \\
\hline lane1-index702-D505-TCCGGAGA-AGGCGAAG-CA-MH070 & $\begin{array}{l}\text { ILCGGAGA- } \\
\triangle G_{G A C G \Delta \triangle A_{7}}\end{array}$ & 728 & $7,821,994$ & 34.71 & 290406 & $3.71 \%$ & 206.5 & 135165 & 120 & 135285 \\
\hline lane1-index07-CAGATC-Qd1 & CAGATC & 826 & $8,837,518$ & 35.79 & 241152 & $2.73 \%$ & 173.5 & 135155 & 197 & 135352 \\
\hline lane1-index03-TTAGGC_Qd3 & TTAGGC & 684 & $7,255,918$ & 36.09 & 129861 & $1.79 \%$ & 92.4 & 135215 & 147 & 135362 \\
\hline lane1-index04-TGACCA_Qd4 & TGACCA & 671 & $7,082,146$ & 36.2 & 98189 & $1.39 \%$ & 69.4 & 135166 & 190 & 135356 \\
\hline lane1-index05-ACAGTG_Qd5 & ACAGTG & 803 & $8,590,947$ & 36.02 & 157466 & $1.83 \%$ & 111.3 & 135166 & 190 & 135356 \\
\hline lane1-index08-ACTTGA-Qd6 & ACTTGA & 803 & $8,506,833$ & 36.08 & 206509 & $2.43 \%$ & 149.1 & 135113 & 246 & 135359 \\
\hline lane1-index06-GCCAAT_Qd9 & GCCAAT & 855 & $8,990,739$ & 36.3 & 222537 & $2.48 \%$ & 160.0 & 135154 & 197 & 135351 \\
\hline lane1-index01-ATCACG_Qd10 & ATCACG & 613 & $6,450,784$ & 36.26 & 103182 & $1.60 \%$ & 73.4 & 135192 & 167 & 135359 \\
\hline lane1-index702-D506-TCCGGAGA-TAATCTTA-CA-MH-073 & $\begin{array}{l}\text { ICLGGAGA- } \\
\text { TADTCTTA }\end{array}$ & 723 & $7,741,604$ & 34.87 & 535794 & $6.92 \%$ & 385.7 & 135240 & 78 & 135318 \\
\hline lane1-index701-D507-ATTACTCG-CAGGACGT-CA-DAV-MH035 & & 581 & $6,202,948$ & 34.89 & 282616 & $4.56 \%$ & 201.8 & 134991 & 179 & 135170 \\
\hline lane1-index702-D507-TCCGGAGA-CAGGACGT-IL-MOR-MH092 & & 825 & $8,766,240$ & 35.02 & 450494 & $5.14 \%$ & 323.2 & 135315 & 77 & 135392 \\
\hline lane1-index701-D501-ATTACTCG-TATAGCCT-AZ-CH-11 & & 635 & $6,784,452$ & 35.13 & 365201 & $5.38 \%$ & 262.7 & 135319 & 77 & 135396 \\
\hline lane1-index705-D507-ATTCAGAA-CAGGACGT-QUGA4_CA_1 & & 806 & $8,492,498$ & 35.23 & 624694 & $7.36 \%$ & 438.5 & 135273 & 77 & 135350 \\
\hline lane1-index705-D508-ATTCAGAA-GTACTGAC-QUGA4_OR_1 & & 713 & $7,594,074$ & 35.02 & 97511 & $1.28 \%$ & 57.6 & 135244 & 85 & 135329 \\
\hline lane1-index702-D503-TCCGGAGA-CCTATCCT-CA-DAV-MH53 & ( & 836 & $8,975,916$ & 34.69 & 272176 & $3.03 \%$ & 193.1 & 135244 & 137 & 135381 \\
\hline lane1-index706-D506-GAATTCGT-TAATCTTA-QULY_MO_1 & & 859 & $9,182,292$ & 34.08 & 226311 & $2.46 \%$ & 159.9 & 135315 & 72 & 135387 \\
\hline lane1-index706-D504-GAATTCGT-GGCTCTGA-QULY_GA_1 & & 782 & $8,374,828$ & 33.84 & 445477 & $5.32 \%$ & 311.2 & 135316 & 72 & 135388 \\
\hline lane1-index703-D503-CGCTCATT-CCTATCCT-IL-SH-187 & & 856 & $9,352,144$ & 33.94 & 229705 & $2.46 \%$ & 161.9 & 135316 & 79 & 135395 \\
\hline lane1-index703-D502-CGCTCATT-ATAGAGGC-IL-SH-186 & & 845 & $9,059,634$ & 34.85 & 279190 & $3.08 \%$ & 198.7 & 135305 & 92 & 135397 \\
\hline lane1-index708-D503-TAATGCGC-CCTATCCT-QUMA2_QU_1 & & 1,089 & $11,585,406$ & 35.34 & 303174 & $2.62 \%$ & 202.9 & 135299 & 91 & 135390 \\
\hline lane1-index707-D501-CTGAAGCT-TATAGCCT-QUMA2_KS_1 & & 339 & $3,863,516$ & 29.22 & 101898 & $2.64 \%$ & 70.1 & 135302 & 87 & 135389 \\
\hline lane1-index708-D505-TAATGCGC-AGGCGAAG-QUMA2_WI_3 & & 1,126 & $11,974,486$ & 35.43 & 371944 & $3.11 \%$ & 254.5 & 135319 & 77 & 135396 \\
\hline lane1-index702-D502-TCCGGAGA-ATAGAGGC-CA-DAV-MH50 & ILLGGAGA- & 1,004 & $10,683,146$ & 35.12 & 472335 & $4.42 \%$ & 336.8 & 135302 & 84 & 135386 \\
\hline
\end{tabular}




\begin{tabular}{|c|c|c|c|c|c|c|c|c|c|c|}
\hline lane1-index709-D503-CGGCTATG-CCTATCCT-QUMI_MO_1 & $\begin{array}{l}\text { CGOLIAIG- } \\
\text { SOTATSCT }\end{array}$ & 484 & $5,195,530$ & 34.92 & 280918 & $5.41 \%$ & 196.1 & 135334 & 71 & 135405 \\
\hline lane1-index709-D502-CGGCTATG-ATAGAGGC-QUMI_IN_1 & $\begin{array}{l}\text { CGGLIAIG- } \\
\triangle T \Delta G \Delta G G C P\end{array}$ & 782 & $8,368,284$ & 35.17 & 336682 & $4.02 \%$ & 232.1 & 135312 & 77 & 135389 \\
\hline lane1-index709-D501-CGGCTATG-TATAGCCT-QUMI_IL_1 & $\begin{array}{ll}\text { CGGLAAG- } \\
\text { TATAGCST }\end{array}$ & 886 & $9,457,046$ & 35.32 & 372635 & $3.94 \%$ & 256.2 & 135330 & 73 & 135403 \\
\hline lane1-index701-D506-ATTACTCG-TAATCTTA-CA-DAV-MH051 & $\begin{array}{l}\text { AIIACILG- } \\
\text { TADTCTTA }\end{array}$ & 808 & $8,604,404$ & 35.42 & 367184 & $4.27 \%$ & 263.5 & 135305 & 77 & 135382 \\
\hline lane1-index709-D504-CGGCTATG-GGCTCTGA-QUMO5_CH_1 & $\begin{array}{l}\text { CEOLIAAIG- } \\
\text { GGCTCTGA }\end{array}$ & 1,147 & $12,336,068$ & 34.64 & 911239 & $7.39 \%$ & 645.2 & 135258 & 69 & 135327 \\
\hline lane1-index09-GATCAG-Opb_13 & GATCAG & 437 & $4,588,607$ & 36.18 & 359604 & $7.84 \%$ & 263.3 & 135167 & 198 & 135365 \\
\hline lane1-index10-TAGCTT-Opb_21 & TAGCTT & 510 & $5,439,434$ & 35.84 & 395156 & $7.26 \%$ & 288.6 & 135190 & 170 & 135360 \\
\hline lane1-index11-GGCTAC-Opb_26 & GGCTAC & 1,097 & $11,586,375$ & 36.11 & 458704 & $3.96 \%$ & 332.8 & 135256 & 109 & 135365 \\
\hline lane1-index12-CTTGTA-Opl_19 & CTTGTA & 548 & $6,060,445$ & 34.78 & 147333 & $2.43 \%$ & 105.8 & 135351 & 25 & 135376 \\
\hline lane1-index13-AGTCAA-Opl_20 & AGTCAA & 1,067 & $11,235,782$ & 36.19 & 244356 & $2.17 \%$ & 175.4 & 135363 & 17 & 135380 \\
\hline lane1-index14-AGTTCC-Opl_21 & AGTTCC & 362 & $4,067,301$ & 34.17 & 85682 & $2.11 \%$ & 61.0 & 135350 & 25 & 135375 \\
\hline lane1-index15-ATGTCA-Oto_14 & ATGTCA & 532 & $5,876,125$ & 35.02 & 68037 & $1.16 \%$ & 47.6 & 135341 & 20 & 135361 \\
\hline lane1-index16-CCGTCC-Oto_3 & CCGTCC & 501 & $5,366,529$ & 35.29 & 72884 & $1.36 \%$ & 51.8 & 135341 & 22 & 135363 \\
\hline lane1-index19-GTGAAA-Ovl_2 & GTGAAA & 632 & $6,650,148$ & 36.22 & 113363 & $1.70 \%$ & 81.3 & 135189 & 164 & 135353 \\
\hline lane1-index20-GTGGCC-Ovl_4 & GTGGCC & 1,330 & $14,000,378$ & 36.25 & 295851 & $2.11 \%$ & 212.4 & 135330 & 23 & 135353 \\
\hline lane1-index18-GTCCGC-OvI_14 & GTCCGC & 453 & $4,778,643$ & 36.21 & 111867 & $2.34 \%$ & 80.8 & 135342 & 21 & 135363 \\
\hline lane1-index21-GTTTCG_Qkor_2 & GTTTCG & 343 & $3,747,744$ & 35.72 & 122680 & $3.27 \%$ & 88.4 & 135322 & 25 & 135347 \\
\hline lane1-index22-CGTACG_Qkor_7 & CGTACG & 584 & $6,320,652$ & 35.5 & 106471 & $1.68 \%$ & 75.5 & 135320 & 24 & 135344 \\
\hline lane2-index19-GTGAAA_Qkor_8 & GTGAAA & 618 & $6,579,237$ & 35.77 & 239676 & $3.64 \%$ & 174.6 & 135342 & 28 & 135370 \\
\hline lane1-index25-ACTGAT-Qm_14 & ACTGAT & 1,445 & $15,243,269$ & 36.3 & 87766 & $0.58 \%$ & 59.0 & 135344 & 22 & 135366 \\
\hline lane1-index27-ATTCCT-Qm_18 & АТTCCT & 986 & $10,380,621$ & 36.21 & 206516 & $1.99 \%$ & 148.4 & 135343 & 32 & 135375 \\
\hline lane2-index01-ATCACG-Qm_20 & ATCACG & 793 & $8,320,777$ & 36.27 & 116218 & $1.40 \%$ & 82.8 & 135353 & 10 & 135363 \\
\hline lane2-index15-ATGTCA-Qm_42 & ATGTCA & 660 & $6,926,209$ & 36.26 & 228592 & $3.30 \%$ & 166.1 & 135353 & 10 & 135363 \\
\hline lane2-index16-CCGTCC-Qm_44 & CCGTCC & 725 & $7,604,072$ & 36.21 & 154351 & $2.03 \%$ & 110.8 & 135340 & 22 & 135362 \\
\hline lane2-index18-GTCCGC-Qm_49 & GTCCGC & 778 & $8,149,115$ & 36.22 & 147999 & $1.82 \%$ & 106.4 & 135348 & 12 & 135360 \\
\hline lane2-index02-CGATGT-Qm_65 & CGATGT & 481 & $5,143,973$ & 35.79 & 95571 & $1.86 \%$ & 68.0 & 135140 & 212 & 135352 \\
\hline lane2-index03-TTAGGC-Qm_68 & TTAGGC & 432 & $4,712,797$ & 35.52 & 120385 & $2.55 \%$ & 86.1 & 135311 & 24 & 135335 \\
\hline lane2-index04-TGACCA-Qm_71 & TGACCA & 370 & $4,306,265$ & 33.52 & 113799 & $2.64 \%$ & 81.3 & 135125 & 233 & 135358 \\
\hline lane1-index23-GAGTGG-Qm_SUW_4 & GAGTGG & 605 & $6,315,482$ & 36.24 & 501129 & $7.93 \%$ & 366.2 & 135369 & 2 & 135371 \\
\hline lane1-index702-D508-TCCGGAGA-GTACTGAC-IL-MOR-MH103 & ILCGGAGA- & 454 & $4,868,858$ & 34.83 & 133092 & $2.73 \%$ & 94.0 & 135274 & 112 & 135386 \\
\hline lane1-index703-D505-CGCTCATT-AGGCGAAG-IL-SH-57 & $\triangle G G C G \Delta \Delta G$ & 825 & $8,855,086$ & 34.87 & 225532 & $2.55 \%$ & 158.6 & 135324 & 77 & 135401 \\
\hline lane1-index702-D501-TCCGGAGA-TATAGCCT-CA-DAV-MH49 & $\begin{array}{l}\text { ICLGGAGA- } \\
\text { TATAGSTT }\end{array}$ & 570 & $6,102,298$ & 34.9 & 271728 & $4.45 \%$ & 194.4 & 135308 & 78 & 135386 \\
\hline lane2-index05-ACAGTG-HB_175 & ACAGTG & 505 & $5,282,756$ & 35.99 & 113388 & $2.15 \%$ & 81.5 & 135354 & 15 & 135369 \\
\hline lane2-index06-GCCAAT-HB_181 & GCCAAT & 1,203 & $12,628,934$ & 35.98 & 303839 & $2.41 \%$ & 218.5 & 135358 & 14 & 135372 \\
\hline lane1-index709-D505-CGGCTATG-AGGCGAAG-QUPE2_PO_1 & $\begin{array}{l}\text { CGGLIAIGE } \\
\text { AGGGGAAG }\end{array}$ & 1,561 & $16,719,416$ & 34.87 & 648087 & $3.88 \%$ & 445.5 & 135256 & 72 & 135328 \\
\hline lane2-index07-CAGATC-MST_29 & CAGATC & 815 & $8,500,932$ & 36.29 & 646991 & $7.61 \%$ & 472.7 & 135366 & 11 & 135377 \\
\hline lane2-index08-ACTTGA-MST_30 & ACTTGA & 785 & $8,199,460$ & 36.24 & 583314 & $7.11 \%$ & 426.4 & 135367 & 11 & 135378 \\
\hline lane2-index09-GATCAG-MST_31 & GATCAG & 368 & $3,850,987$ & 36.06 & 359410 & $9.33 \%$ & 263.1 & 135359 & 13 & 135372 \\
\hline lane1-index710-D503-TCCGCGAA-CCTATCCT-QUPR2_VA_1 & $\begin{array}{l}\text { ILLGLGAA- } \\
\text { ISTATrPT }\end{array}$ & 863 & $9,251,870$ & 34.83 & 343156 & $3.71 \%$ & 235.0 & 135312 & 77 & 135389 \\
\hline
\end{tabular}


lane1-index703-D501-CGCTCATT-TATAGCCT-IL-SH-096

lane1-index709-D506-CGGCTATG-TAATCTTA-QUPR2_NC_1

lane1-index710-D502-TCCGCGAA-ATAGAGGC-QUPR2_PN _

lane2-index27-ATTCCT-ARK_15

lane2-index10-TAGCTT-B2_1

lane1-index710-D505-TCCGCGAA-AGGCGAAG-QURO2_RU_1

lane2-index12-CTTGTA-PIE_6

lane2-index11-GGCTAC-PIE_10

lane2-index23-GAGTGG-SVT_6

lane2-index25-ACTGAT-SVT_11

lane2-index13-AGTCAA-TAM_1

lane2-index14-AGTTCC-TAM_10

lane2-index21-GTTTCG-WR4_1

lane2-index22-CGTACG-WR4_ 7

lane1-index711-D502-TCTCGCGC-ATAGAGGC-QUST_IA_1

lane1-index711-D501-TCTCGCGC-TATAGCCT-QUST_GA_2

lane1-index701-D508-ATTACTCG-GTACTGAC-CA-DAV-MH14

lane1-index702-D504-TCCGGAGA-GGCTCTGA-CA-MH068

lane1-index701-D504-ATTACTCG-GGCTCTGA-CA-DAV-MH039

\begin{tabular}{|c|c|c|c|c|c|c|c|c|c|}
\hline 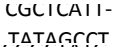 & 817 & $8,751,196$ & 34.92 & 226311 & $2.59 \%$ & 159.9 & 135310 & 78 & 135388 \\
\hline CGGLIAIG- & 890 & $9,499,730$ & 35.33 & 151100 & $1.59 \%$ & 95.8 & 135313 & 79 & 135392 \\
\hline$\triangle T \Delta G_{7} \Delta G_{1} A_{1}$ & 1,171 & $12,484,692$ & 35.17 & 303079 & $2.43 \%$ & 203.1 & 135328 & 74 & 135402 \\
\hline АТTCCT & 1,064 & $11,915,961$ & 34.94 & 403126 & $3.38 \%$ & 290.4 & 135340 & 28 & 135368 \\
\hline TAGCTT & 997 & $10,376,834$ & 36.38 & 357705 & $3.45 \%$ & 258.5 & 135378 & 12 & 135390 \\
\hline 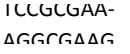 & 1,632 & $17,470,594$ & 35 & 818393 & $4.68 \%$ & 567.7 & 135285 & 72 & 135357 \\
\hline CTTGTA & 611 & $6,366,688$ & 36.37 & 303781 & $4.77 \%$ & 220.5 & 135360 & 11 & 135371 \\
\hline GGCTAC & 1,765 & $18,332,609$ & 36.41 & 950637 & $5.19 \%$ & 690.9 & 135374 & 5 & 135379 \\
\hline GAGTGG & 977 & $10,224,657$ & 36.21 & 287688 & $2.81 \%$ & 211.4 & 135384 & 9 & 135393 \\
\hline ACTGAT & 544 & $6,371,705$ & 34.4 & 162957 & $2.56 \%$ & 115.8 & 135368 & 18 & 135386 \\
\hline AGTCAA & 641 & $6,702,004$ & 36.21 & 269096 & $4.02 \%$ & 195.3 & 135350 & 13 & 135363 \\
\hline AGTTCC & 739 & $7,760,332$ & 36.02 & 331159 & $4.27 \%$ & 240.8 & 135350 & 11 & 135361 \\
\hline GTTTCG & 190 & $2,851,967$ & 28.17 & 18161 & $0.64 \%$ & 11.5 & 135071 & 311 & 135382 \\
\hline CGTACG & 351 & $4,913,182$ & 27.47 & 17859 & $0.36 \%$ & 10.7 & 135079 & 349 & 135428 \\
\hline DTAGASGST- & 545 & $5,810,094$ & 35.2 & 203778 & $3.51 \%$ & 138.4 & 135302 & 76 & 135378 \\
\hline TATAGSCT & 756 & $8,106,672$ & 34.65 & 98394 & $1.21 \%$ & 60.1 & 135280 & 105 & 135385 \\
\hline GTACTGAC & 744 & $7,957,296$ & 34.84 & 240512 & $3.02 \%$ & 170.8 & 135002 & 136 & 135138 \\
\hline GGCTRTA- & 682 & $7,347,776$ & 34.31 & 410357 & $5.58 \%$ & 294.5 & 135036 & 151 & 135187 \\
\hline GASTITTGA & 639 & $6,877,046$ & 34.74 & 309340 & $4.50 \%$ & 221.1 & 135291 & 79 & 135370 \\
\hline
\end{tabular}


Sheet1

\begin{tabular}{llcc} 
species & clade and region & all oaks & North American oaks \\
\cline { 2 - 3 } chrysolepis & Protobalanus & $\mathrm{x}$ & $\mathrm{x}$ \\
tomentella & Protobalanus & $\mathrm{x}$ & $\mathrm{x}$ \\
vacciniifolia & Protobalanus & $\mathrm{x}$ & $\mathrm{x}$ \\
robur & White oaks - Eurasia & $\mathrm{x}$ & \\
petraea & White oaks - Eurasia & $\mathrm{x}$ & \\
mongolica & White oaks - Eurasia & $\mathrm{x}$ & $\mathrm{x}$ \\
garryana & White oaks - California & $\mathrm{x}$ & $\mathrm{x}$ \\
berberidifolia & White oaks - California & $\mathrm{x}$ & $\mathrm{x}$ \\
douglasii & White oaks - California & $\mathrm{x}$ & $\mathrm{x}$ \\
lobata & White oaks - California & $\mathrm{x}$ \\
montana & White oaks - Eastern North America & $\mathrm{x}$ & $\mathrm{X}$ \\
michauxii & White oaks - Eastern North America & $\mathrm{x}$ & $\mathrm{x}$ \\
alba & White oaks - Eastern North America & $\mathrm{x}$ & $\mathrm{X}$ \\
lyrata & White oaks - Eastern North America & $\mathrm{x}$ & $\mathrm{x}$ \\
bicolor & White oaks - Eastern North America & $\mathrm{x}$ & $\mathrm{x}$ \\
macrocarpa & White oaks - Eastern North America & $\mathrm{x}$ & $\mathrm{x}$ \\
muehlenbergii & White oaks - Eastern North America & $\mathrm{x}$ & $\mathrm{x}$ \\
prinoides & White oaks - Eastern North America & $\mathrm{x}$ & $\mathrm{x}$ \\
boyntonii & White oaks - Eastern North America & $\mathrm{x}$ & $\mathrm{x}$ \\
margarettae & White oaks - Eastern North America & $\mathrm{x}$ & $\mathrm{x}$ \\
stellata & White oaks - Eastern North America & $\mathrm{x}$ & $\mathrm{x}$ \\
engelmannii & White oaks - Western North America & $\mathrm{x}$ & $\mathrm{x}$ \\
arizonica & White oaks - Western North America & $\mathrm{x}$ & $\mathrm{x}$ \\
mohriana & White oaks - Western North America & $\mathrm{x}$ & $\mathrm{x}$ \\
vaseyana & White oaks - Western North America & $\mathrm{x}$ & \\
& & &
\end{tabular}


Sheet1

$\underline{\text { North American white oaks }}$ North American oaks without California eastern North American white oaks $x$

$\mathrm{X}$

$\mathrm{X}$

$\mathrm{X}$

$\mathrm{X}$

$\mathrm{X}$

$x$

$x$

$x$

$x$

$x$

$x$

$x$

$x$

$x$

$x$

$x$

$x$

$x$

$\mathrm{x}$

$x$

$x$

$x$

$x$

$x$

$x$

$x$

$x$

$x$

$x$

$x$
$x$

$x$

$x$ $x$

$\mathrm{X}$

$\mathrm{X}$

$\mathrm{X}$

$\mathrm{X}$

$X$

$\mathrm{X}$

$\mathrm{X}$

X

X

X

Page 2 
All oaks

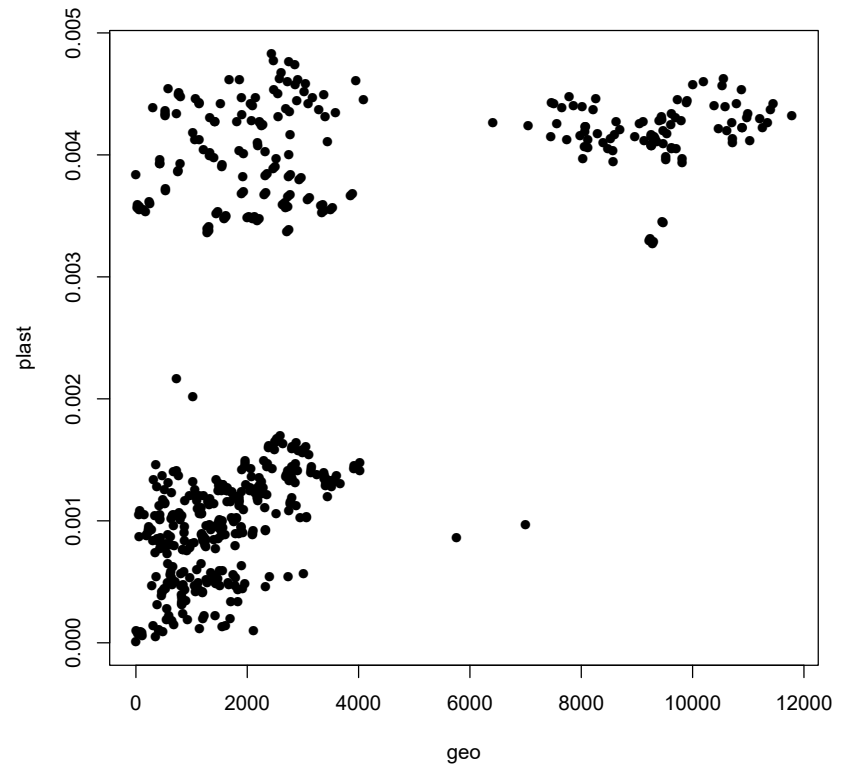

North American white oaks without California, Quercus engelmannii excluded

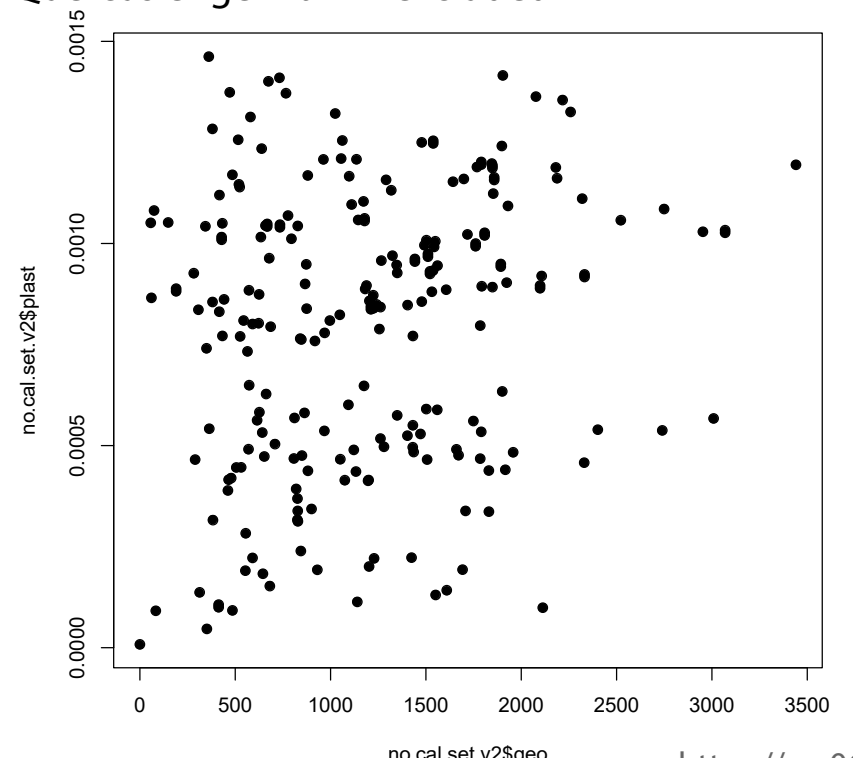

North American oaks only

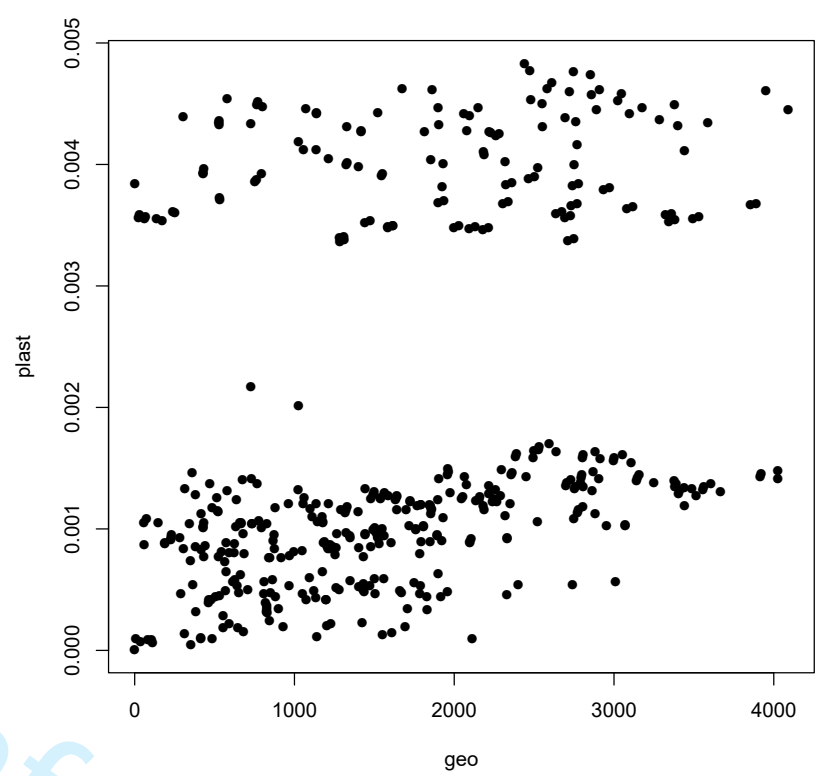

North American white oaks without California

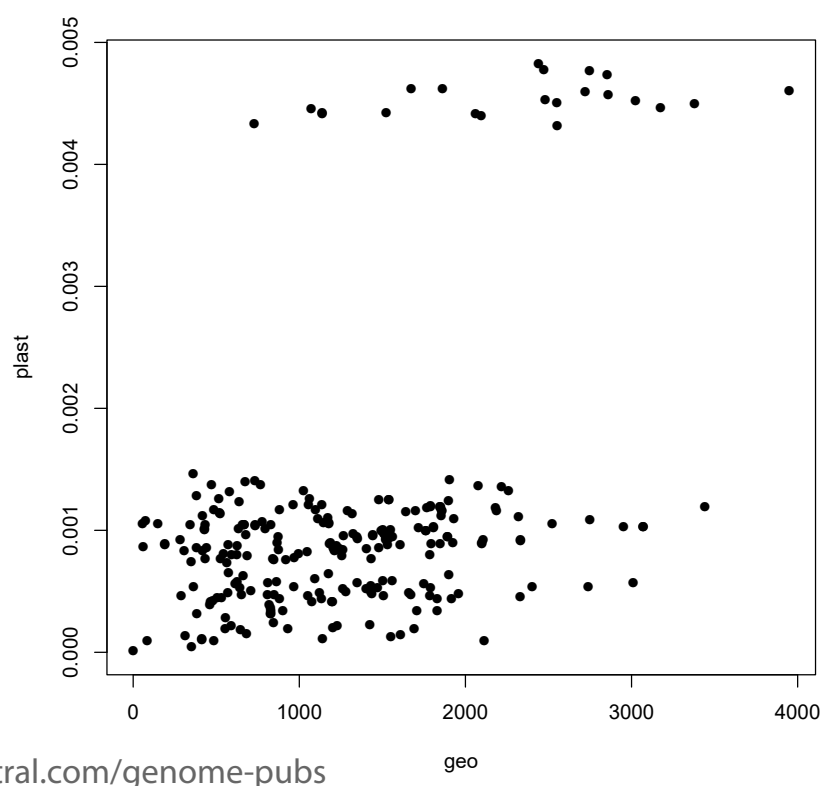

